\title{
MATERIAIS LAMELARES DE TI APLICADOS EM PROCESSOS FOTOCATALÍTICOS
}

\author{
Nailma J. Martins ${ }^{\mathrm{a}, *,(\text {, }}$, Luele R. S. Barbosa ${ }^{\mathrm{a}}$, Vitor E. P. Cota ${ }^{\mathrm{a}}$ e Henrique A. J. L. Mourão ${ }^{\mathrm{a}, \#}$ \\ ${ }^{a}$ Universidade Federal dos Vales do Jequitinhonha e Mucuri, 39100-000, Diamantina - MG, Brasil
}

Recebido em 22/06/2021; aceito em 22/11/2021; publicado na web em 20/01/2022

\begin{abstract}
Ti-LAYERED MATERIALS APPLIED IN PHOTOCATALYTIC PROCESSES. Titanium (Ti)-layered materials have interesting characteristics for photocatalytic applications, such as the high specific surface area and ease of intercalation of species in the interlamellar region, which are extremely favorable for the surface processes. In this sense, this review addresses the data available in the literature related to the preparation, structure and main photocatalytic applications of Ti-layered materials. The main synthesis methodologies of these materials were addressed: the hydrothermal, which is mainly used to obtain powders (containing $\mathrm{TiO}_{2}$ or titanates) and the anodization process that is commonly used to obtain films composed mainly of $\mathrm{TiO}_{2}$ nanotubes. Prominent photocatalytic applications for semiconductors were also addressed, focusing on the use of pure or associated Ti-layered materials for the photodegradation of emerging pollutants, photoreduction of $\mathrm{CO}_{2}$ or metals, hydrogen production and the inactivation of microorganisms. It was possible to observe that, despite these being extremely promising materials and with outstanding efficiency in some processes, such materials can still be considered little explored and deserve greater attention from researchers in the area.
\end{abstract}

Keywords: $\mathrm{TiO}_{2}$; titanates; layered; synthesis; photocatalytic applications.

\section{INTRODUÇÃO}

Devido ao atual cenário de crise energética e ambiental que o planeta se encontra, é imprescindível a busca por soluções que promovam a remediação ambiental e a geração de energia limpa. Neste sentido, a preocupação com a qualidade e formas eficientes para o tratamento da água são temáticas recorrentes, especialmente devido à enorme quantidade de resíduos oriundos de fármacos e agrotóxicos, normalmente despejados no meio aquático de diferentes formas. ${ }^{1-6} \mathrm{~A}$ contaminação com agrotóxicos no Brasil, por exemplo, deve se agravar devido às recentes liberações de diversos agrotóxicos nos últimos anos, sendo alguns já banidos em outros países por serem considerados altamente tóxicos para a saúde humana e meio ambiente. ${ }^{7}$ Por outro lado, a geração de energia renovável é atualmente um dos assuntos de maior destaque no momento e foi abordado exaustivamente pelos diferentes líderes mundiais na cúpula do clima de 2021. ${ }^{8,9}$

A fotocatálise heterogênea com semicondutores é uma alternativa promissora para o enfrentamento desses problemas ambientais e desafios energéticos, especialmente quando se considera a possibilidade de utilizar energia solar, como fonte de energia, na ativação fotocatalítica dos materiais semicondutores. ${ }^{10-12}$ Embora exista enorme quantidade de estudos em pequena escala, essa tecnologia pode ser considerada incipiente em termos de aplicação e ainda depende do desenvolvimento de materiais mais eficientes, baratos, estáveis, ativos sob radiação solar e de fácil aplicação em larga escala, entre outras características que podem contribuir para a consolidação desta tecnologia. ${ }^{13-16}$

Quando tratamos de fotocatálise com semicondutores, o material de maior destaque é o dióxido de titânio $\left(\mathrm{TiO}_{2}\right)$. $\mathrm{O} \mathrm{TiO}_{2}$ é um material à base de titânio (Ti), pioneiro na fotocatálise, sendo notável que as suas propriedades fotocatalíticas vêm sendo exaustivamente estudadas pela comunidade científica mundial nos últimos anos. ${ }^{17-19} \mathrm{O}^{\mathrm{TiO}_{2}}$ foi relatado pela primeira vez, como material fotoativo, em 1929, quando construções pintadas à base de $\mathrm{TiO}_{2}$ branquearam ao serem irradiadas pelo sol e no ano de 1956 foi noticiado como fotocatalisador

*e-mail: nailmajanauba@gmail.com

\#e-mail alternativo: henrique.mourao@ict.ufvjm.edu.br na oxidação de diferentes solventes orgânicos, tais como álcoois e hidrocarbonetos. ${ }^{20,21}$ Esse semicondutor foi o mais estudado nas aplicações fotocatalíticas no período entre os anos de 1992 e 2020, sendo que entre as 48.786 publicações sobre fotocatálise, as que envolvem o $\mathrm{TiO}_{2}$ correspondem a $56 \%$ desses trabalhos na Web of Science. Esse interesse no $\mathrm{TiO}_{2}$ se deve principalmente à sua elevada eficiência, mantendo-se estável nos processos fotocatalíticos, além de ser um material atóxico, barato, super-hidrofílico e um semicondutor do tipo $n$ (o que lhe garante maior mobilidade eletrônica). ${ }^{21-29}$

Independente da fase cristalina do material, que é um fator extremamente importante, outra característica importante do fotocatalisador é a sua área superficial, visto que os processos fotocatalíticos com semicondutores são efetivados por reações de oxirredução que ocorrem na superfície do semicondutor. ${ }^{30-32}$ Nesse sentido, existem materiais à base de Ti emergentes em aplicações fotocatalíticas, sendo eles os materiais lamelares à base de Ti que incluem o $\mathrm{TiO}_{2}$ e diferentes titanatos, com morfologias e propriedades peculiares tais como a possibilidade de intercalação e a alta área superficial. ${ }^{33-35}$ Dentre os materiais à base de Ti, os lamelares apresentariam desempenho melhor nas aplicações fotocatalíticas devido às suas propriedades promissoras, contudo, é evidenciado na Figura 1 que, apesar desse diferencial, eles ainda não são muito explorados. .2,36,37 $^{2}$

Nesse sentido, este artigo de revisão possui como objetivo abordar a literatura atual, relacionada ao uso desses materiais em fotocatálise heterogênea, discutindo as potencialidades e desafios dessa área. Para isto, são abordadas as principais metodologias de síntese dos materiais lamelares à base de Ti, propriedades e suas aplicações. Esta revisão descreve aplicações dos materiais lamelares, à base de Ti, focadas, especialmente, na área ambiental e produção de energia, aplicações promissoras para esse segmento de materiais, especialmente em escala nanométrica.

\section{MATERIAIS À BASE DE Ti}

Materiais à base de Ti têm sido investigados em diversas aplicações, como em processos fotovoltaicos, biomateriais, catalisadores e em baterias. ${ }^{38-40}$ Reitera-se que o $\mathrm{TiO}_{2}$ tem sido 


\section{Evolução de Publicações}

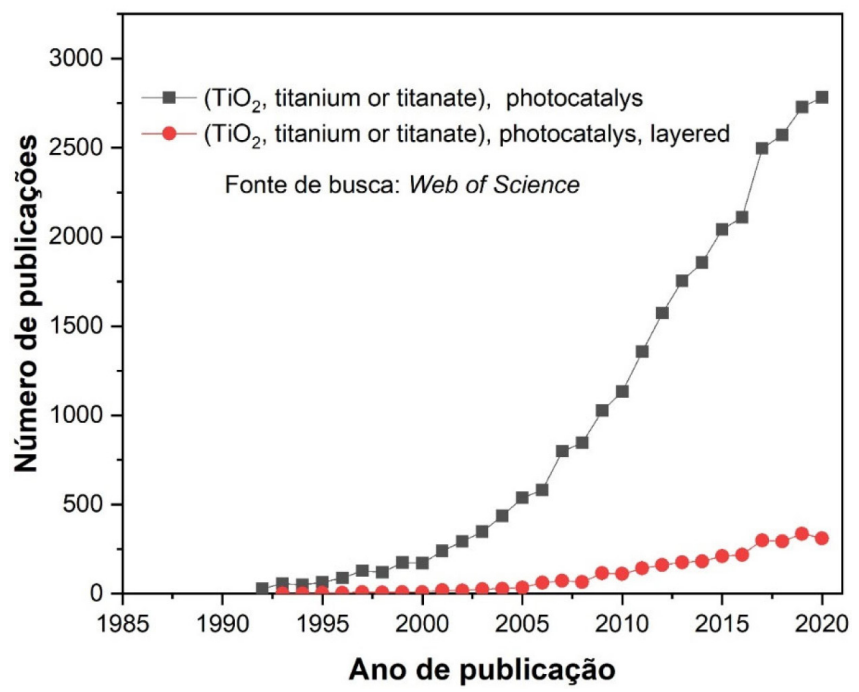

Figura 1. Dados obtidos da 'web of science' mostrando a evolução no número das publicações entre os anos de 1992 e 2020. Busca realizada usando os termos: $\mathrm{TiO}_{2}$, Titanium (Ti), titanate, photocatalysis e layered

amplamente utilizado em aplicações fotocatalíticas voltadas para o desenvolvimento de tecnologias para a química verde. ${ }^{17,23-26,41}$

Além do $\mathrm{TiO}_{2}$, outra classe de materiais à base de Ti que tem se destacado são os titanatos. Esses compostos são inorgânicos e apresentam diferentes composições e simetrias com a fórmula molecular monoclínica $\mathrm{M}_{2} \mathrm{Ti}_{\mathrm{n}} \mathrm{O}_{2 \mathrm{n}+1}$ (em que $\mathrm{M}$ é principalmente hidrogênio, lítio $(\mathrm{Li})$, sódio $(\mathrm{Na})$, potássio $(\mathrm{K})$ e outros metais; e $\mathrm{n}$ varia entre 2 e 8). ${ }^{42,43}$ De acordo com Silva et al. ${ }^{44}$ e Catti et at..$^{43}$, os titanatos são formados por octaedros de $\mathrm{TiO}_{6}$ (Figura 2A) que se conectam através do oxigênio que está em um vértice do octaedro, de modo a construir camadas paralelas escalonadas, dando origem a uma estrutura bidimensional, como pode ser observado na Figura 2B, orientados ao longo da direção [010]. São representantes da família dos titanatos lamelares: metatitanato de sódio $\left(\mathrm{Na}_{2} \mathrm{Ti}_{3} \mathrm{O}_{7}\right)$, titanato

A)
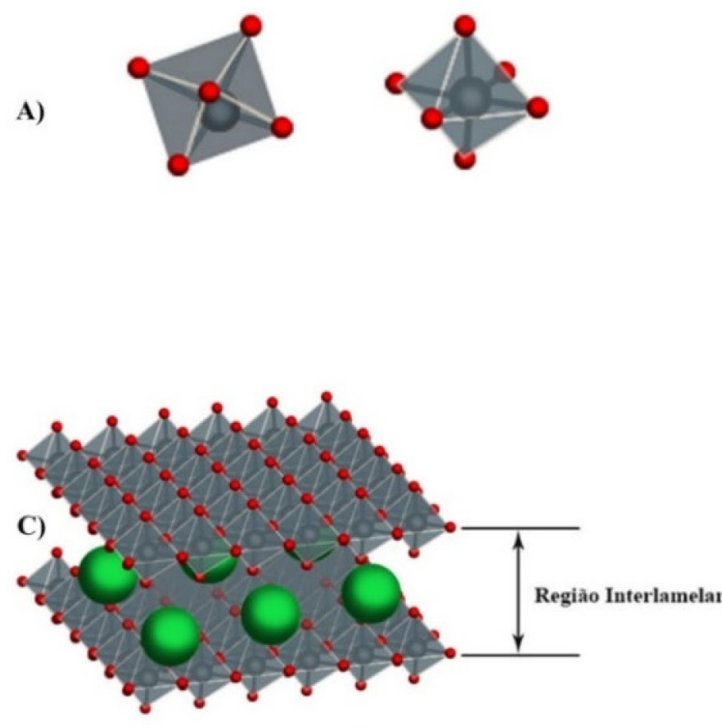

Espécie química de potássio $\left(\mathrm{K}_{2} \mathrm{Ti}_{2} \mathrm{O}_{5}\right)$ e tetratitanato de potássio $\left(\mathrm{K}_{2} \mathrm{Ti}_{4} \mathrm{O}_{9}\right)$, que apresentam estrutura de octaedros ligados pelos vértices, sendo tais unidades combinadas abaixo e acima em forma zig-zag, formando estruturas em degraus. ${ }^{45}$

Um material formado por camadas é denominado material lamelar e a formação das lamelas ocorre por ligações químicas entre os átomos do material. $\mathrm{O}$ espaço que separa duas lamelas adjacentes é denominado de região interlamelar e, nessa região, é possível realizar a intercalação de íons e moléculas de diversos tamanhos, capazes de alterar as propriedades químicas, físicas e mecânicas do composto. As lamelas interagem entre si por meio de forças de natureza física. ${ }^{42,46} \mathrm{O}$ termo intercalação refere-se ao ato da inserção reversível de espécies químicas, dentro dos sítios reticulares vazios do material. Essa troca provoca alterações importantes nas propriedades (ex: ópticas e eletrônicas), tanto na matriz como no intercalante, além de conduzir a novas funcionalidades e aplicações. ${ }^{47-55}$

Conforme apresentado por Silva et al.,${ }^{44}$ considerando-se a fórmula molecular $\mathrm{M}_{2} \mathrm{Ti}_{\mathrm{n}} \mathrm{O}_{2 \mathrm{n}+1}$ para os titanatos lamelares, quando $\mathrm{n} \leq 5$, o titanato possui a estrutura aberta (Figura 2C) e boa capacidade de troca iônica. Todavia, quando $n>5$ a estrutura é do tipo túnel (Figura 2D) e apresenta capacidade de troca iônica menor, porém é mais estável que os titanatos com $n \leq 5$. Algumas estruturas de materiais lamelares apresentam o formato de nanotubos similares aos nanotubos de carbono apresentados por Iijima. ${ }^{53}$ Para ambas as estruturas (aberta ou do tipo túnel) os cátions podem ficar intercalados no espaço interlamelar e compensar a carga negativa das folhas de $\mathrm{TiO}_{6} \cdot{ }^{51}$

A estabilidade é uma característica importante a ser avaliada nesses materiais. Papp et al. ${ }^{51}$ avaliaram a estabilidade térmica de $\mathrm{Na}_{2} \mathrm{Ti}_{3} \mathrm{O}_{7}$ e $\mathrm{Na}_{2} \mathrm{Ti}_{6} \mathrm{O}_{13}$, os resultados indicaram que a estrutura do túnel de $\mathrm{Na}_{2} \mathrm{Ti}_{6} \mathrm{O}_{13}$ tem maior estabilidade térmica, em comparação com a estrutura em camadas de $\mathrm{Na}_{2} \mathrm{Ti}_{3} \mathrm{O}_{7}$. Wang et al. ${ }^{52}$ investigaram as propriedades catalíticas de diferentes titanatos de potássio com $\mathrm{n}=2$, 4 e $6\left(\mathrm{~K}_{2} \mathrm{Ti}_{2} \mathrm{O}_{5}, \mathrm{~K}_{2} \mathrm{Ti}_{4} \mathrm{O}_{9}\right.$ e $\left.\mathrm{K}_{2} \mathrm{Ti}_{6} \mathrm{O}_{13}\right)$, sintetizados pelo método de reação de estado sólido variando-se a temperatura de calcinação e a proporção dos precursores submetidos à reação. Os resultados evidenciaram diferentes energias de ligação, sendo que a estrutura

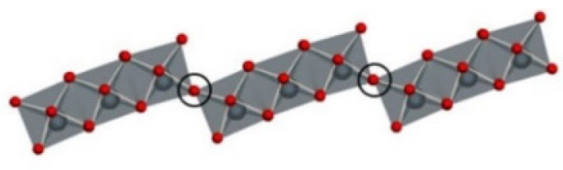

B)

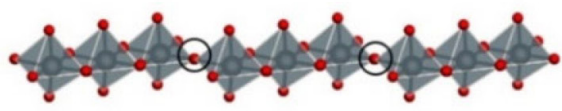

D)

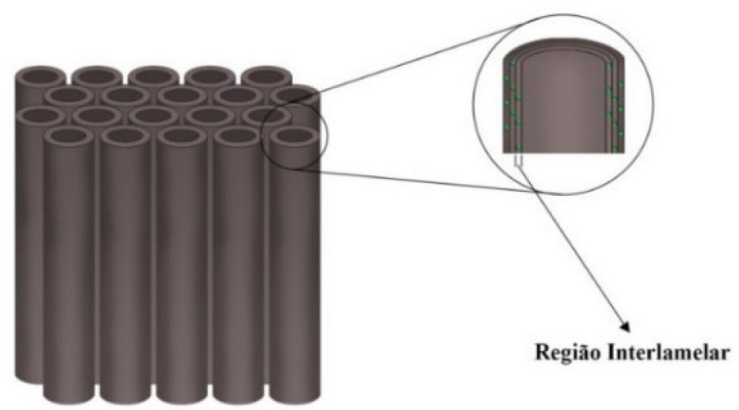

Átomo de oxigênio

Átomo de titânio

Figura 2. Estrutura dos titanatos lamelares do tipo $\mathrm{M}_{2} \mathrm{Ti}_{n} \mathrm{O}_{2 n+1}$ : A) Unidade de repetição octaedro; B) Octaedros conectados formando faixa; C) Estrutura do tipo aberta e D) Estrutura do tipo túnel 
em camada $\mathrm{K}_{2} \mathrm{Ti}_{2} \mathrm{O}_{5}$ apresentou energia de ligação e desempenho catalítico maiores do que as estrutura $\mathrm{K}_{2} \mathrm{Ti}_{4} \mathrm{O}_{9}$ e $\mathrm{K}_{2} \mathrm{Ti}_{6} \mathrm{O}_{13}$.

Em geral, os titanatos lamelares possuem padrão de difração de raios $\mathrm{X}$ com um pico de difração (ou banda) basal característico, um pico a aproximadamente $10^{\circ}$ (identificado por *) que é relativo às difrações ocorridas na região interlamelar (ver ilustração da Figura 2C). Além disso, os difratogramas dos titanatos lamelares possuem normalmente picos alargados e ruidosos (especialmente em rotinas de medida rápidas), sendo essas características relacionadas com o grau de organização, intercalação e o número de lamelas do material. Adicionalmente, os difratogramas teóricos para outras fases de $\mathrm{Ti}$ (anatase, rutilo e brookita) normalmente apresentam picos mais definidos do que o difratograma dos titanatos lamelares. Os materiais lamelares de Ti podem intercalar vários íons metálicos e compostos orgânicos, e por troca iônica é possível a preparação de novos compostos, de acordo com os parâmetros de sínteses de "soft chemistry" como, por exemplo, no trabalho de Sasaki et al.,${ }^{45}$ no qual foi realizada a síntese de titanatos de lítio, a partir da troca iônica em titanatos hidratados em camadas. A intercalação de íons dos titanatos e a troca iônica já foram exploradas em aplicações ambientais como adsorção de íons em efluentes, como apresentado nos trabalhos de Zhang et al..$^{56}$ que utilizaram titanatos como adsorventes para amônio catiônico $\left(\mathrm{NH}_{4}^{+}\right)$. Os autores avaliaram cinco titanatos (titanato de lítio, titanato de sódio, titanato de potássio, titanato de estrôncio e titanato de bário) amorfos, com diferentes contraíons, e os resultados indicaram que o raio iônico e a valência dos contraíons intercalados afetam o equilíbrio de troca iônica.

Seguindo a investigação da intercalação em estruturas lamelares de Ti, nos estudos de Sun et al. ${ }^{57}$ foram sintetizados nanotubos de titanatos de sódio. Nesse trabalho, foi apontado que a estabilidade térmica dos nanotubos é resultado da presença dos íons sódio entre as camadas e que o processo de troca iônica foi alcançado após a agitação em solução catiônica com íons de metais de transição. Os autores provaram que, após a troca iônica, os nanotubos eram os mesmos implicando na manutenção da estrutura tubular. No entanto, a área superficial variou de acordo com o contraíon presente na região interlamelar. Além disso, a energia de band gap dos titanatos substituídos diminuiu, garantindo assim que a permutabilidade iônica forneça um método eficaz para introduzir íons funcionais na estrutura tubular primária dos titanatos.

\section{SÍNTESE DE MATERIAIS LAMELARES DE Ti}

As características físicas e químicas dos materiais lamelares, à base de Ti (área de superfície específica, tamanho da partícula, porosidade, estrutura e a química de superfície, entre outras), influenciam diretamente no desempenho desses materiais em aplicações fotocatalíticas. Algumas dessas características podem ser manipuladas alterando-se um ou mais parâmetros da síntese: reagentes, temperatura, tempo, agitação, entre outras condições de síntese. ${ }^{29,58}$ Estes materiais podem ser sintetizados por diferentes rotas de síntese que podem resultar em diferentes fases cristalinas e morfologias. ${ }^{59,60}$ Dentre as morfologias apresentadas, os nanotubos já foram relatados como preferíveis em várias aplicações, pois a camada interna dos nanotubos ocos fornece uma área de superfície maior e além disso podem ser funcionalizados facilmente pelo preenchimento dessa região. ${ }^{60-64} \mathrm{~A}$ aplicação de titanatos lamelares requer morfologia controlável, que está intimamente relacionada às propriedades de superfície e estrutura cristalina. Assim, elucidar o mecanismo de formação desses materiais é importante para compreender como as condições de síntese afetam suas propriedades.

Muitas técnicas foram desenvolvidas para produzir vários materiais nanoestruturados de Ti com boa fotoatividade, incluindo sol-gel, ${ }^{65}$ síntese hidrotérmica ${ }^{66-70}$ e métodos eletroquímicos. ${ }^{71-74} \mathrm{Na}$ sequência, serão discutidas as duas principais metodologias de síntese utilizadas para a produção de materiais lamelares de Ti, o método hidrotérmico e a anodização, abordando as principais condições utilizadas e as principais características dos materiais obtidos.

\section{Método hidrotérmico}

Uma metodologia que tem atraído grande atenção é o método hidrotérmico, que consiste em realizar reações dentro de recipientes selados, como autoclave e tubo de pressão, como ilustrado na Figura 3A. Essas reações geralmente ocorrem em temperaturas controladas e com pressões acima da atmosférica. ${ }^{75}$ Devido às pressões elevadas, as sínteses hidrotérmicas geralmente ocorrem com menor gasto energético, quando comparadas com processos que exigem calcinação. ${ }^{76}$ Nessas condições, é possível dissolver e recristalizar os materiais durante a síntese, permitindo controlar a nucleação, crescimento, morfologia e cristalinidade dos materiais que seriam relativamente insolúveis sob condições normais, além de ser possível variar diferentes parâmetros de síntese. ${ }^{77-79}$

Normalmente, os materiais lamelares de Ti são sintetizados, sob condições hidrotérmicas utilizando soluções alcalinas. Embora outros parâmetros sejam importantes, tais como o precursor e temperatura, o aumento do $\mathrm{pH}$ da solução aquosa favorece a obtenção de materiais lamelares. ${ }^{37}$ Se o objetivo for obtenção de nanotubos, deve-se utilizar meios extremamente alcalinos, podendo-se ser necessário o uso de

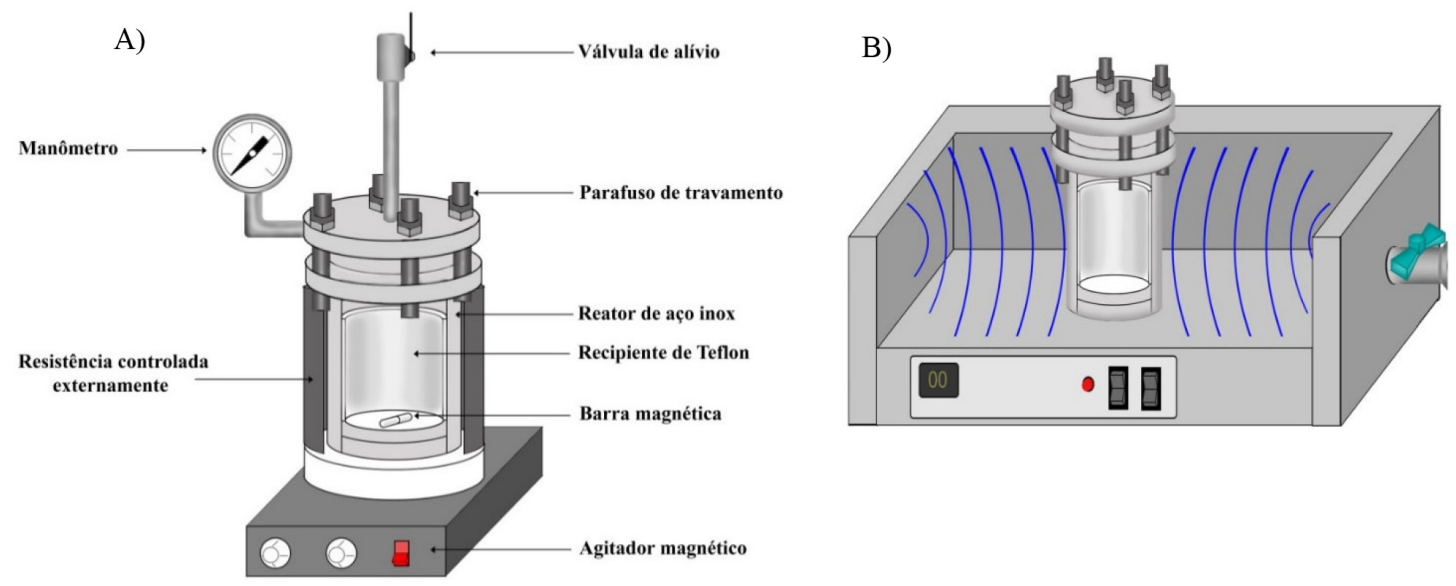

Figura 3. A) Ilustração de um típico reator autoclave com recipiente de Teflon e equipado com um agitador magnético. Uma resistência externa acoplada a um controlador é responsável pelo aquecimento; B) Reator autoclave acoplado a um micro-ondas 
soluções com concentrações de $10 \mathrm{~mol} \mathrm{~L}^{-1}$, dependendo do precursor e da temperatura utilizada. ${ }^{37,66}$

Nesse sentido, An et al. ${ }^{66}$ sintetizaram nanofolhas de titanatos de sódio usando o método hidrotérmico em solução aquosa de $\mathrm{NaOH}$ $10 \mathrm{~mol} \mathrm{~L}{ }^{-1}$, em uma autoclave a $140{ }^{\circ} \mathrm{C}$ por 3 horas. Esse trabalho identificou que a composição das nanofolhas, em solução alcalina concentrada, era de $\mathrm{Na}_{2 \mathrm{x}} \mathrm{H}_{\mathrm{x}} \mathrm{Ti}_{3} \mathrm{O}_{7}(0<\mathrm{x}<2)$ em vez de $\mathrm{Na}_{2} \mathrm{Ti}_{3} \mathrm{O}_{7}$. Os resultados experimentais estão de acordo com a dedução teórica dos autores que constataram que as energias de formação variam de acordo com o pH e, mesmo sob a condição alcalina forte, ainda há troca iônica entre os íons $\mathrm{Na}^{+} \mathrm{e} \mathrm{H}^{+}$.

Outro trabalho que avaliou a síntese hidrotérmica foi o de Chen et al., ${ }^{67}$ que sintetizaram titanato de lítio $\left(\mathrm{Li}_{4} \mathrm{Ti}_{5} \mathrm{O}_{12}\right) \mathrm{em}$ nanofolhas. A reação ocorreu em uma autoclave a $200{ }^{\circ} \mathrm{C}$ por 12 horas, sendo que o precipitado obtido foi, posteriormente, calcinado em uma mufla a $550{ }^{\circ} \mathrm{C}$ por 6 horas. As propriedades eletroquímicas no $\mathrm{Li}_{4} \mathrm{Ti}_{5} \mathrm{O}_{12}$ indicaram desempenho para aplicações em baterias de íons-lítio, com capacidade de descarga de $132 \mathrm{~mA} \mathrm{~h} \mathrm{~g}^{-1}$, após 200 ciclos a $10000 \mathrm{~mA} \mathrm{~g}^{-1}$.

Kapusuz et al. ${ }^{37}$ afirmaram em seus estudos que o aumento da molaridade de íons hidróxidos $\left(\mathrm{OH}^{-}\right)$aumenta a solubilidade dos precursores metálicos e sob pressões autógenas, o limite de saturação é atingido em temperaturas mais baixas e em tempos menores. Neste sentido, o aumento na alcalinidade eleva a taxa de reação hidrotérmica, tendo a taxa de dissolução e precipitação aceleradas na formação de titanatos. Outro trabalho que avaliou a influência de $\mathrm{pH}$ sobre os nanotubos foi apresentado por Nakahira et al. ${ }^{68}$ no qual foi verificada a influência do tratamento ácido em nanotubos de titanatos sintetizados pelo método hidrotérmico. Os autores revelaram que o tratamento ácido leva ao desordenamento dos nanotubos pela alteração significativa dos poliedros $\mathrm{TiO}_{6}$.

Nanotubos de titanato com estrutura semelhante a $\mathrm{H}_{2} \mathrm{Ti}_{2} \mathrm{O}_{5} \cdot \mathrm{H}_{2} \mathrm{O}$ foram sintetizados pelo método hidrotérmico por Huang et al. ${ }^{63}$ utilizando-se o pó de $\mathrm{TiO}_{2}$ anatase como precursor em $\mathrm{NaOH} 8 \mathrm{M}$. Os autores evidenciaram experimentalmente que a temperatura de tratamento afeta a cinética de reação. Além disso, foi demonstrado que as nanofolhas, nanotubos e nanofios de titanatos são possíveis estruturas resultantes da reação entre $\mathrm{TiO}_{2}$ e $\mathrm{NaOH}$ concentrado e o aumento da temperatura pode acelerar o processo de transformação de nanotubo para nanofio, mas não pode afetar a sequência dos eventos de reação que foi primeiramente a formação das nanofolhas, depois dos nanotubos e por último os nanofios.

O estudo de Morgan et al. ${ }^{69}$ avaliou o processo de síntese pelo método hidrotérmico utilizando diferentes fases do precursor cristalino $\mathrm{TiO}_{2}$. A interpretação do processo de dissolução dos precursores indicou que a dissolução da anatase ocorre por meio de um processo cinético de ordem zero, enquanto que a dissolução da fase rutilo ocorre por meio de um processo de segunda ordem. A fase anatase produziu os nanotubos mais rapidamente enquanto o rutilo reagiu de forma incompleta, deixando rutilo remanescente e nanobastões ao final da reação. $\mathrm{O}$ comprimento dos nanotubos também é influenciado pelo tamanho das partículas da fase precursora. De acordo com Dawson et al. ${ }^{70}$ a fase de anatase pura, com um tamanho de partícula de $300 \mathrm{~nm}$, poderia produzir nanotubos com 1 $\mu \mathrm{m}$ de comprimento, enquanto a fase rutilo produziu placas e folhas, independentemente do tamanho de partícula.

O trabalho de Bavykin et al. ${ }^{62}$ forneceu uma análise sistemática da influência da temperatura na morfologia dos nanotubos de $\mathrm{TiO}_{2}$ em síntese hidrotérmica. Os precursores $\mathrm{TiO}_{2}$ na fase anatase e $\mathrm{NaOH}$ $10 \mathrm{~mol} \mathrm{~L}^{-1}$ permaneceram por 22 horas na autoclave em diferentes temperaturas $\left(120\right.$ a $\left.190{ }^{\circ} \mathrm{C}\right)$, sendo que os resultados obtidos indicaram que na faixa de temperatura 120 a $150^{\circ} \mathrm{C}$ o diâmetro médio dos nanotubos é maior, enquanto o aumento na temperatura resulta na diminuição acentuada do volume do poro, devido à formação de nanofibras não ocas. Esse trabalho propõe um mecanismo de transformação de $\mathrm{TiO}_{2}$ cristalino para nanotubos e aponta que o estágio de curvatura é ocasionado pelo desequilíbrio na largura das multicamadas de nanofolhas. Nesse estudo, foram propostos três mecanismos possíveis para a formação de nanotubos de titanato de paredes múltiplas: a rolagem helicoidal de uma nanofolha de camada única, a curvatura de várias nanofolhas conjuntas e a produção direta de um nanotubo de múltiplas camadas (Figura 4). Eles sugeriram que a formação de nanotubos passa pela dissolução de $\mathrm{TiO}_{2}$, acompanhada pelo crescimento de nanofolhas em camadas, sendo que depois acontece a dissolução-recristalização das nanofolhas e a sua curvatura, por último, a troca de íons de sódio por próton durante a lavagem de nanotubos. Outros mecanismos de formação dos nanotubos pelo método hidrotérmico já foram propostos. Alguns trabalhos afirmam que a etapa chave para a formação de nanotubos ocorre durante a reação hidrotérmica. Por outro lado, outros sugerem que a lavagem ácida, após o processo hidrotérmico, é essencial. ${ }^{59,78,80-82}$

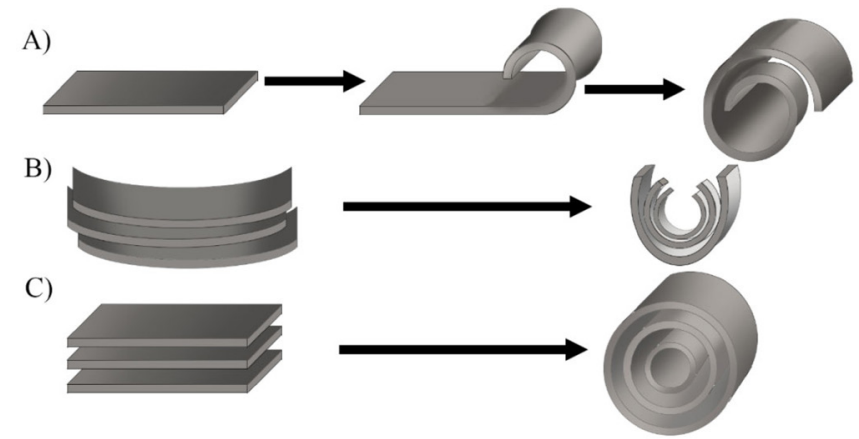

Figura 4. Ilustração do mecanismo proposto para a formação dos nanotubos; A) rolagem helicoidal de uma nanofolha de camada única; B) curvatura de várias nanofolhas conjuntas; C) produção direta de um nanotubo de múltiplas camadas

Caso o solvente utilizado no processo seja orgânico, o método pode ser denominado de solvotermal. ${ }^{77,83}$ Esse método é uma alternativa bastante utilizada quando se pretende um controle mais rigoroso da morfologia do material sintetizado. Assim como o método hidrotérmico alcalino, pode ser utilizado para obtenção de nanotubos como, por exemplo, no trabalho de Nam et al.,${ }^{84}$ no qual foi realizada a síntese de nanotubos de titanatos em um processo solvotérmico utilizando-se uma autoclave a $130{ }^{\circ} \mathrm{C}$ por 24 horas. Entre os solventes orgânicos testados, apenas o metanol, o etanol e metiletilcetona exibiram estruturas de nanotubos e estes apresentaram área superficial de $174,5,168,9$ e $208,8 \mathrm{~m}^{2} / \mathrm{g}$, respectivamente.

Outra estratégia aplicada ao método hidrotérmico é o uso de micro-ondas na preparação dos materiais nanoestruturados (Figura 3B). Nesse tipo de estratégia, as micro-ondas são utilizadas para aumentar a velocidade de síntese em temperaturas mais baixas do que o método hidrotérmico tradicional, bem como a área superficial e a quantidade de poros. ${ }^{76,85}$ Com o auxílio de micro-ondas Preda et al. ${ }^{86}$ sintetizaram nanotubos de titanato de sódio (NaTiNTs) pelo método hidrotérmico com uma solução de $\mathrm{NaOH} 10 \mathrm{~mol} \mathrm{~L}^{-1}$ à temperatura constante de $135^{\circ} \mathrm{C}$, variando-se o tempo de irradiação. Os autores relataram que os NaTiNTs começam a ser formados com 15 minutos de irradiação de micro-ondas, três vezes mais rápido que o método convencional sem micro-ondas. Além disso, os titanatos apresentaram estrutura aberta com paredes múltiplas, diâmetro externo médio de 8 $\mathrm{nm}$ e área de superfície específica de $210 \mathrm{~m}^{2} / \mathrm{g}$. Assim, a combinação de condições hidrotérmicas e irradiação de micro-ondas reduziu significativamente o tempo de reação necessário para a conversão completa das partículas de anatase em NaTiNTs. 


\section{Síntese por anodização}

Outra metodologia de síntese que tem se destacado para a produção de novos materiais é a anodização de metais. ${ }^{87}$ Esse método é muito aplicado na síntese de óxido de alumínio e tem se estendido para outros óxidos, tais como óxidos de Ti, produzindo filmes de óxidos metálicos a baixo custo, com boa uniformidade, com baixa espessura e superfície porosa. ${ }^{71,88} \mathrm{~A}$ anodização consiste em aplicar um campo elétrico sobre dois eletrodos em uma célula eletroquímica, produzindo a reação de geração do óxido, em que o polo positivo recebe o material a ser anodizado e o polo negativo recebe um material inerte de referência. ${ }^{88}$

Segundo Pang et al. ${ }^{61}$ para a produção de nanotubos de $\mathrm{TiO}_{2}$, a anodização pode ser dividida em três gerações, de acordo com as características dos nanotubos sintetizados. Na primeira geração, o comprimento dos nanotubos fica em torno de apenas $0,5 \mu \mathrm{m}$ e o meio eletrolítico à base de ácido fluorídrico (HF). Na segunda geração, os comprimentos podem chegar a $5 \mu \mathrm{m}$ e a solução eletrolítica composta de água contendo íons fluoreto $\left(\mathrm{F}^{-}\right)$provenientes de sais ao invés de HF. Por fim, na terceira geração, os nanotubos apresentam comprimentos mais longos de 100 a $1000 \mu \mathrm{m}$, produzidos em eletrólitos orgânicos contendo íons de flúor. ${ }^{61,89}$

De acordo com Pang et al. ${ }^{61}$ e Roy et al.,${ }^{19}$ no estágio inicial de anodização, uma densa camada de $\mathrm{TiO}_{2}$ é formada na superfície da placa de titânio por oxidação e a migração de íons ocorre dentro da interface metal/óxido de metal, sob o campo elétrico aplicado. Os íons de titânio podem se dissolver e reagir com o íon oxigênio $\left(\mathrm{O}^{2-}\right)$ ou com o íon hidroxila $\left(\mathrm{OH}^{-}\right)$fornecido pela água para formar o $\mathrm{TiO}_{2}$ ou hidróxido de titânio, respectivamente (Figura 5).

No estágio seguinte, a placa de titânio e a camada de óxido, em contato com o eletrólito, são dissolvidas por íons fluoreto $\left(\mathrm{F}^{-}\right)$ formando o complexo hexafluorotitânio, resultando na formação de minúsculos pits na camada de óxido e, gradualmente, em poros maiores, com o aumento do tempo de anodização. ${ }^{61}$ Quando a taxa de corrosão eletroquímica é igual à taxa de dissolução química dos nanotubos, o comprimento do tubo permanece o mesmo. ${ }^{19}$ Assim, a etapa final determina o comprimento dos nanotubos durante a reação. Na Figura 5 é apresentado o processo de anodização para formação dos nanotubos de $\mathrm{TiO}_{2}$, sendo a célula eletroquímica à esquerda da seta a representação do início do processo, ou seja, ainda não há formação dos nanotubos. A célula eletroquímica à direita da seta representa o estado da célula após a formação dos nanotubos, com os íons $\mathrm{F}^{-}$e $\mathrm{H}^{+}$na solução. As reações representadas acima da seta são as que ocorrem no estágio inicial da anodização e a reação representada abaixo da seta é a reação que ocorre no estágio seguinte, com a formação do complexo hexafluorotitânio.

Entre as vantagens desse método está o controle sobre variáveis relacionadas ao processo, tais como: tensão aplicada, tempo de anodização, distância ânodo-cátodo, $\mathrm{pH}$, concentração e temperatura da solução eletrolítica. ${ }^{71-73,90}$ Devido à regularidade da estrutura porosa, os filmes finos de $\mathrm{TiO}_{2}$ tubular são atualmente usados na indústria de células fotovoltaicas, como camadas anti-refletivas na maior parte das células solares, em implantes dentários pelas propriedades biomédicas do óxido poroso, além do uso do material como catalisador. ${ }^{88}$

Dependendo das condições utilizadas na célula eletroquímica (ex: tipo de eletrólito e voltagem), a camada de óxido sólido pode ser compacta ou nanotubular (nanoporosa). ${ }^{91} \mathrm{O}$ tipo de eletrólito utilizado na anodização é essencial para determinar o tipo de morfologia eventualmente formada. $\mathrm{O} \mathrm{pH}$ do eletrólito afeta o comportamento de auto-organização do nanotubo ao afetar a taxa de dissolução do $\mathrm{TiO}_{2} \cdot{ }^{90}$ Geralmente quando a solução de anodização contém íons de flúor (ou íons de perclorato, cloreto ou brometo), o filme anódico de $\mathrm{TiO}_{2}$ desenvolverá uma morfologia porosa e tubular. ${ }^{89} \mathrm{O}$ titânio e o óxido de titânio são facilmente dissolvidos em eletrólitos à base de fluoreto, particularmente aqueles que contêm ácido fluorídrico e assim, ocasiona a oxidação assistida formando camadas porosas e tubulares..$^{90}$

$\mathrm{O}$ comprimento dos nanotubos de $\mathrm{TiO}_{2}$ é frequentemente regulado pelo tempo de tratamento de anodização. Alijani et al. ${ }^{92}$ sintetizaram camadas espessas de nanotubos de $\mathrm{TiO}_{2}$ por $15 \mathrm{~min}$ de anodização, otimizando o eletrólito de trabalho. Verificou-se que a adição de ácido láctico no eletrólito $\mathrm{NH}_{4} \mathrm{~F} / \mathrm{H}_{2} \mathrm{O}$ /etilenoglicol evita a quebra dielétrica, permitindo a anodização em potenciais mais elevados $(160 \mathrm{~V})$ e obtendo nanotubos espessos ( $80 \mu \mathrm{m}$ de espessura e $170 \mathrm{~nm}$ de diâmetro médio). No trabalho de Montakhab et al., ${ }^{74}$ foi investigada a influência simultânea da agitação e do aumento no tempo de anodização na síntese de nanotubos de $\mathrm{TiO}_{2}$. Nesse estudo, foi utilizada solução de etilenoglicol contendo $0,3 \%$ em peso de fluoreto de amônio $\left(\mathrm{NH}_{4} \mathrm{~F}\right)$ e água como eletrólito, potencial de $30 \mathrm{~V}$ e diferentes tempos de anodização (75, 105 e 180 minutos). Foi relatado que o tempo prolongado, com agitação durante a anodização, introduziu danos estruturais na parte superior do nanotubo como resultado do efeito de corrosão excessiva. Além disso, o emprego de ultrassom como fonte agitadora levou à obtenção de nanotubos totalmente abertos. Adicionalmente, os resultados da espectroscopia de reflectância difusa UV-Vis (DRS, diffuse reflectance spectroscopy) não indicaram diferença na energia do band gap para diferentes etapas e tempos de anodização.

Outros tipos de eletrólitos já foram utilizados como, por exemplo, no trabalho de Fahim, et al. ${ }^{73}$ em que as condições de anodização (ex: voltagem aplicada) foram otimizadas para a síntese de nanotubos de titânia em eletrólitos livres de fluoreto. Na síntese utilizando como eletrólito o ácido perclórico $\left(\mathrm{HClO}_{4}\right)$ a $0,1 \mathrm{~mol} \mathrm{~L}^{-1}$ de $\mathrm{pH}$ igual a aproximadamente 1 e com voltagem de $20 \mathrm{~V}$, os nanotubos apresentaram um comprimento de cerca de $30 \mu \mathrm{m}$. Para

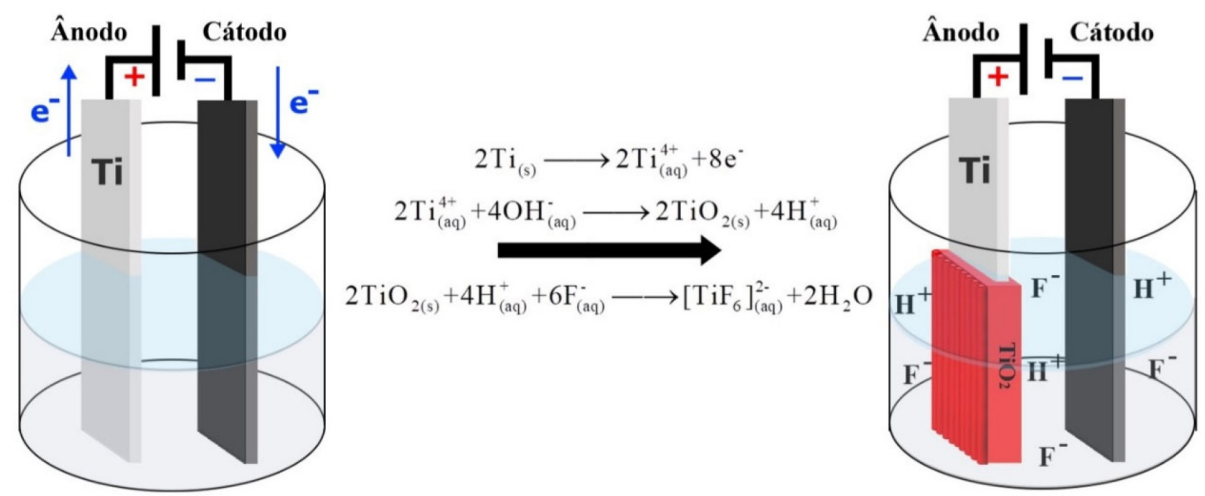

Figura 5. Ilustração do mecanismo de anodização para a formação dos nanotubos de TiO ${ }_{2}$ em eletrólito com íons flúor dissolvidos 
os nanotubos preparados em cloreto de sódio $(\mathrm{NaCl})$ a $0,3 \mathrm{~mol} \mathrm{~L}^{-1} \mathrm{e}$ de $\mathrm{pH} 4,3$, o comprimento foi acima de $50 \mu \mathrm{m}$ e, na anodização em ácido sulfúrico $\left(\mathrm{H}_{2} \mathrm{SO}_{4}\right)$ aquoso, o comprimento de tubo foi acima de $0,5 \mu \mathrm{m}$. Outros autores que utilizaram eletrólito livre de fluoretos foram Jaroenworaluck et al.,${ }^{93}$ que realizaram a síntese de nanotubos de $\mathrm{TiO}_{2}$ com eletrólito aquoso e glicerol. Nesse trabalho, após a anodização, os nanotubos foram tratados termicamente na faixa de temperatura $200-600^{\circ} \mathrm{C} \mathrm{em}$ atmosfera de ar, sendo que os nanotubos se mantiveram estáveis até $550{ }^{\circ} \mathrm{C}$. Acima dessa temperatura, a sinterização das nanopartículas domina, a densificação ocorre e a morfologia do nanotubo se perde.

Após o processo de anodização, os nanotubos de $\mathrm{TiO}_{2}$ formados, geralmente, estão na forma amorfa. Assim, em alguns casos, a calcinação após a anodização se faz necessária para aumentar a cristalinidade. ${ }^{90}$ Nesse sentido, o tratamento térmico posterior ao processo de anodização foi investigado, a fim de avaliar as mudanças na estrutura cristalina dos nanotubos. Varghese et al. ${ }^{94}$ avaliaram a estabilidade estrutural dos nanotubos de Ti sintetizados por anodização e submetidos a diferentes temperaturas em ambientes secos e úmidos. A cristalização dos nanotubos na fase anatase foi identificada, a partir de $280{ }^{\circ} \mathrm{C}$, independente das condições ambientais, enquanto a fase rutilo se formou a $620^{\circ} \mathrm{C}$ em ambientes secos e $570{ }^{\circ} \mathrm{C}$ em ambientes úmidos. Em todos os casos, a arquitetura dos nanotubos foi considerada estável até $580{ }^{\circ} \mathrm{C}$ e, acima dessa temperatura, o crescimento de grãos no suporte de titânio leva à ruptura dos nanotubos, devido às mudanças no diâmetro do poro da fase romboédrica.

O diâmetro e a espessura da parede dos nanotubos sintetizados por anodização podem ser ajustados, alterando a voltagem anódica aplicada. Correlações lineares entre o diâmetro dos nanotubos e a voltagem anódica aplicada foram relatadas em muitos estudos anteriores. ${ }^{91,90}$ Nanotubos de $\mathrm{TiO}_{2}$ também foram sintetizados, por Sreekantan et al., ${ }^{36}$ pelo método de anodização, variando-se a voltagem e a temperatura de calcinação. Com a variação da tensão de anodização, os autores conseguiram controlar as propriedades da superfície dos nanotubos e verificou-se que a propriedade catalítica do material é influenciada diretamente por sua morfologia. De tal forma, os autores relataram que o material sintetizado com a tensão de $5 \mathrm{~V}$ apresentou sítios ativos e uma estrutura nanoporosa, enquanto que o material sintetizado com $20 \mathrm{~V}$ apresentou nanotubos bem alinhados e uniformes, sendo que nessas condições os nanotubos calcinados a $400{ }^{\circ} \mathrm{C}$ contribuíram para um bom desempenho na degradação do corante laranja de metila, pois essa temperatura favorece a cristalinidade da amostra.

Adicionalmente aos trabalhos discutidos no presente texto, a Tabela 1 apresenta algumas referências publicadas nos últimos anos sobre a síntese, morfologia e os principais objetivos dos estudos sobre materiais lamelares de Ti. Uma análise sistemática dos dados da literatura revela que o método hidrotérmico é o método principal utilizado para a obtenção de materiais lamelares de Ti em pó, enquanto que a anodização é utilizada visando à obtenção de filmes. Além disso, podemos citar alguns métodos ou procedimentos auxiliares/ complementares que podem ser utilizados, tais como o método sol-gel ou processos de calcinação utilizados de forma preliminar ou após o principal processo de síntese.

\section{APLICAÇÕES DE MATERIAIS LAMELARES DE TITÂNIO}

Existem diferentes estratégias de otimização das propriedades dos materiais lamelares à base de Ti, tais como a dopagem, estruturas hibrídas, co-catalisadores, inserção de espécies químicas e intercalação que conferem alterações nas propriedades ópticas e eletrônicas e melhoram a eficiência no processo fotocatalítico. ${ }^{19,47-50,117,118}$ Os materiais à base de $\mathrm{Ti}$ já foram aplicados em diversos processos fotoquímicos, em diversas áreas, tais como a ambiental, geração de energia e inibição microbiana. ${ }^{48,119}$ A Figura 6 exemplifica as diferentes aplicações envolvendo os materiais lamelares à base de Ti. Na área ambiental, temos a Figura 6A com a fotodegradação de poluentes; na Figura 6B, fotorredução de dióxido de carbono $\left(\mathrm{CO}_{2}\right)$; na Figura 6C, geração de $\mathrm{H}_{2}$ e na Figura 6D, inibição microbiana.
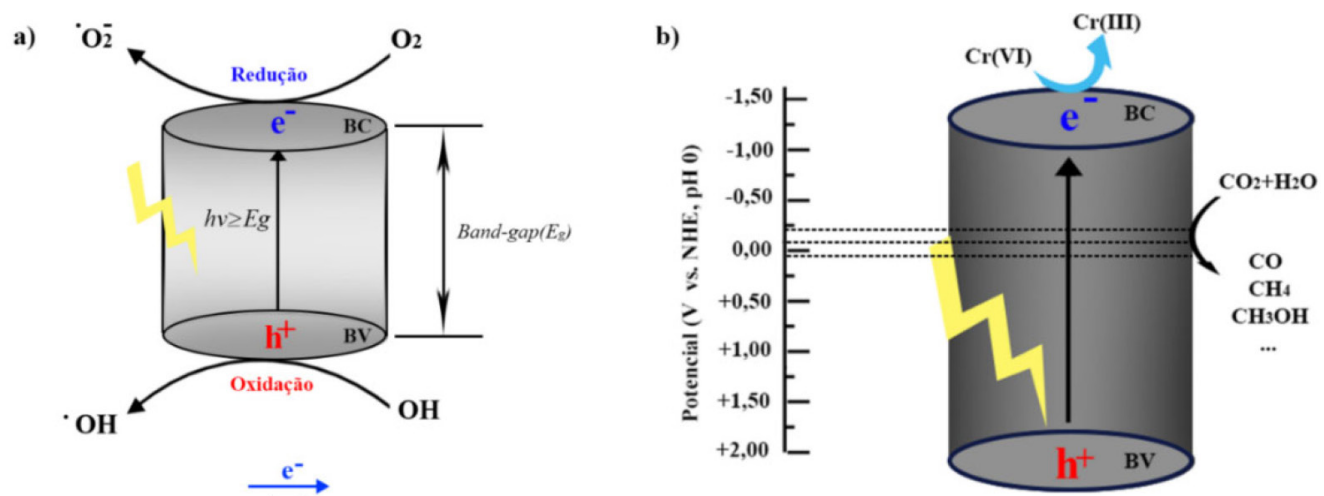

c)

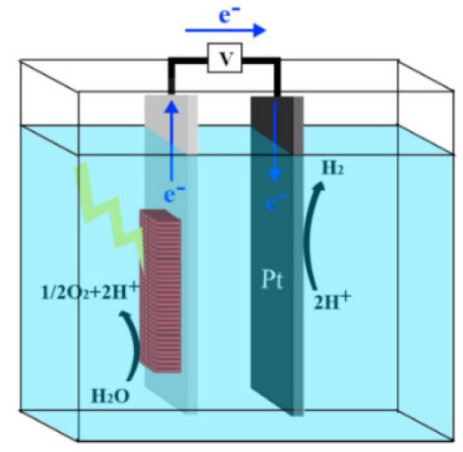

d)

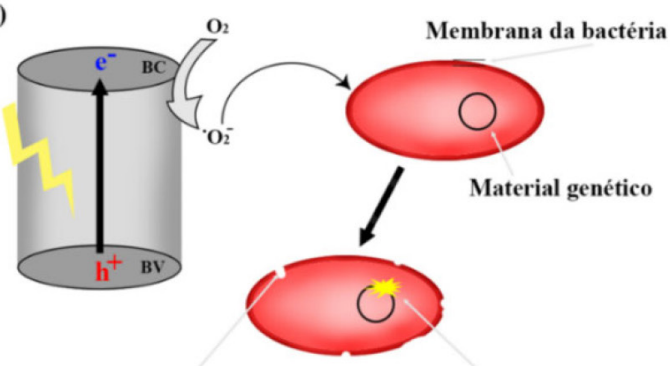

Membrana rompida

Dano ao material genético

Figura 6. A) Esquema de ativação do fotocatalisador e geração de cargas e radicais no processo fotocatalítico heterogêneo com semicondutores; B) Processo de fotorredução de $\mathrm{CO}_{2}$ e fotorredução de $\mathrm{Cr}(\mathrm{VI})$; C) Ilustração do mecanismo de produção de $\mathrm{H}_{2}$; D) Processo de inativação de microorganismos com destruição da membrana plasmática 
Tabela 1. Métodos de síntese de materiais lamelares à base de Ti, morfologias e os principais objetivos dos estudos

\begin{tabular}{|c|c|c|c|c|}
\hline Material & Método de síntese & Morfologia & Objetivo & Ref \\
\hline Titanatos de Sódio & Hidrotérmico & Nanotubos & $\begin{array}{c}\text { Avaliação da capacidade } \\
\text { catalítica }\end{array}$ & {$[78]$} \\
\hline $\mathrm{H}_{2} \mathrm{Ti}_{3} \mathrm{O}_{7}$ & Hidrotérmico & Nanotubos & $\begin{array}{l}\text { Desenvolvimento de superca- } \\
\text { pacitor }\end{array}$ & [95] \\
\hline $\begin{array}{l}\mathrm{Na}_{0,036} \mathrm{H}_{1,964} \mathrm{Ti}_{3} \mathrm{O}_{7} \\
3,52 \mathrm{H}_{2} \mathrm{O}\end{array}$ & Hidrotérmico & Nanotubos & $\begin{array}{c}\text { Estudos sobre as propriedades } \\
\text { elétricas }\end{array}$ & [96] \\
\hline $\mathrm{H}_{2} \mathrm{Ti}_{2} \mathrm{O}_{5} \cdot \mathrm{H}_{2} \mathrm{O}$ & Hidrotérmico & Nanotubos & Armazenamento eletroquímico & {$[46]$} \\
\hline $\begin{array}{l}\mathrm{A}_{2} \mathrm{Ti}_{\mathrm{n}} \mathrm{O}_{2 \mathrm{n}+1} \\
\mathrm{~A}=\mathrm{Li}, \mathrm{Na}, \mathrm{K}\end{array}$ & Hidrotérmico & Nanotubos & Fotodegradação de clorofórmio & {$[97]$} \\
\hline $\mathrm{K}_{2} \mathrm{Ti}_{8} \mathrm{O}_{17}$ & Hidrotérmico & Nanofios & $\begin{array}{l}\text { Estudo de estabilidade térmica } \\
\text { e área de superfície }\end{array}$ & {$[98]$} \\
\hline Nanotubo de titânio & Hidrotérmico & Nanotubos & $\begin{array}{c}\text { Célula solar sensibilizada com } \\
\text { corante }\end{array}$ & [99] \\
\hline $\mathrm{TiO}_{2}$ & Hidrotérmico & Nanotubos & $\begin{array}{l}\text { Estudo sobre o mecanismo de } \\
\text { formação dos nanotubos }\end{array}$ & {$[100]$} \\
\hline $\mathrm{K}_{2} \mathrm{Ti}_{6} \mathrm{O}_{13}$ & Hidrotérmico & Nanofios & $\begin{array}{l}\text { Elucidar o mecanismo de } \\
\text { crescimento dos nanofios }\end{array}$ & {$[37]$} \\
\hline Titanatos de potássio & Hidrotérmico & Nanofitas em forma de túnel & $\begin{array}{c}\text { Estudos estruturais, vibracio- } \\
\text { nais e troca iônica }\end{array}$ & {$[44]$} \\
\hline Titanato de sódio & Hidrotérmico & Nanotubos & $\begin{array}{c}\text { Emissão de luminescência para } \\
\text { dispositivos ópticos }\end{array}$ & {$[54]$} \\
\hline $\mathrm{Na}_{2} \mathrm{Ti}_{3} \mathrm{O}_{7}$ & Hidrotérmico & Nanofibras & $\begin{array}{l}\text { Estudos estruturais após adsor- } \\
\text { ção de íons metálicos }\end{array}$ & {$[55]$} \\
\hline $\mathrm{TiO}_{2}$ & Hidrotérmico & Nanofios & Evolução fotocatalítica de $\mathrm{H}_{2}$ & [101] \\
\hline Titanatos & Hidrotérmico & Nanotubos & Aplicações em células solares. & {$[102]$} \\
\hline cqds $/ \mathrm{K}_{2} \mathrm{Ti}_{6} \mathrm{O}_{13}$ & Hidrotérmico com calcinação & Nanotubos & Degradação de Amoxicilina & {$[103]$} \\
\hline $\mathrm{TiO}_{2}$ & Hidrotérmico com calcinação & Nanofolhas & Processos fotocatalíticos & {$[104]$} \\
\hline $\mathrm{TiO}_{2}$ & Hidrotérmico com calcinação & Nanotubos & $\begin{array}{l}\text { Avaliação do efeito da calci- } \\
\text { nação }\end{array}$ & [105] \\
\hline Óxidos de titânio & Anodização & Nanotubos & $\begin{array}{l}\text { Estudo do mecanismo de } \\
\text { síntese }\end{array}$ & {$[71]$} \\
\hline $\mathrm{TiO}_{2}$ & Anodização & Nanotubos & Estudos de fotoluminescência & [106] \\
\hline $\mathrm{TiO}_{2}$ & Anodização & Nanotubos & $\begin{array}{c}\text { Avaliação da sensibilidade e } \\
\text { seletividade }\end{array}$ & {$[107]$} \\
\hline Titânia anatase & Anodização & Nanotubos & $\begin{array}{c}\text { Eletrodos de células solares } \\
\text { sensibilizadas }\end{array}$ & [108] \\
\hline $\mathrm{Pt} / \mathrm{TiO}_{2}$ & Anodização & Nanotubos & Fotoeletrocatálise de corante & [109] \\
\hline $\mathrm{TiO}_{2}$ & Anodização & Nanotubos & $\begin{array}{l}\text { Estudo e desenvolvimento de } \\
\text { rota de síntese }\end{array}$ & {$[72]$} \\
\hline $\mathrm{TiO}_{2}$ & Anodização & Nanotubos & $\begin{array}{c}\text { Estudo sobre a formação de } \\
\text { nanotubos }\end{array}$ & [110] \\
\hline $\mathrm{TiO}_{2}$ & Organogel & Nanotubos & $\begin{array}{c}\text { Estudo sobre a formação da } \\
\text { estrutura helicoidal }\end{array}$ & [111] \\
\hline $\mathrm{Na}_{0,66} \mathrm{Li}_{0,22} \mathrm{Ti}_{0,78} \mathrm{O}_{2}$ & $\begin{array}{c}\text { Sol-gel e reação em estado } \\
\text { sólido }\end{array}$ & Camadas & $\begin{array}{c}\text { Aplicações em baterias de } \\
\text { íon } \mathrm{Na}\end{array}$ & [112] \\
\hline $\mathrm{TiO}_{2}$ & Sol-gel & Nanotubos & $\begin{array}{c}\text { Estudos sobre a obtenção de } \\
\text { nanotubos }\end{array}$ & [113] \\
\hline $\mathrm{Li}_{2} \mathrm{Ti}_{3} \mathrm{O}_{7}$ e $\mathrm{Na}_{2} \mathrm{Ti}_{3} \mathrm{O}_{7}$ & Troca Iônica & Camadas & $\begin{array}{l}\text { Estudos sobre a estrutura em } \\
\text { camadas e troca iônica }\end{array}$ & {$[42]$} \\
\hline \multicolumn{5}{|l|}{$\mathrm{A}_{2} \mathrm{Ti}_{\mathrm{n}} \mathrm{O}_{2 \mathrm{n}+1}$} \\
\hline $\mathrm{A}=\mathrm{Li}, \mathrm{Na}, \mathrm{K}$ & Troca Iônica & Camadas & $\begin{array}{c}\text { Avaliação da estabilidade de } \\
\text { titanatos alcalinos }\end{array}$ & {$[43]$} \\
\hline $\begin{array}{l}\mathrm{M}_{\mathrm{x}} \mathrm{Ti}_{2-\mathrm{x} / 3} \mathrm{Li}_{\mathrm{x} / 3} \mathrm{O}_{4} \\
\mathrm{M}=\mathrm{K}^{+}, \mathrm{Li}^{+}, \mathrm{Na}^{+}\end{array}$ & Reação em estado sólido & Camadas & $\begin{array}{c}\text { Decomposição fotocatalítica } \\
\text { seletiva }\end{array}$ & [114] \\
\hline $\mathrm{Li}_{2} \mathrm{Ti}_{3} \mathrm{O}_{7}$ & Reação em estado sólido & Nanotubos & $\begin{array}{c}\text { Geração de células a com- } \\
\text { bustível }\end{array}$ & {$[115]$} \\
\hline $\mathrm{TiO}_{2}$ & Deposição de Camada Atômica & Nanotubos & Aplicação em células Solares & {$[116]$} \\
\hline
\end{tabular}


Todas essas aplicações envolvendo o uso de luz para ativação dos materiais.

\section{Aplicações ambientais de materiais lamelares de Ti}

Os materiais lamelares de $\mathrm{Ti}$ cristalinos com propriedades semicondutoras podem ser aplicados na fotocatálise heterogênea, com a finalidade de fotodegradação de compostos orgânicos, sendo assim uma tecnologia para descontaminação ambiental. ${ }^{32} \mathrm{O}$ mecanismo de reação dessa fotodegradação ocorre através dos processos oxidativos avançados (POAs) em que o semicondutor é ativado pela absorção da radiação luminosa que é igual ou maior que a energia do band gap do material (Figura 6A). Isso levará à excitação e transferência de elétrons $(e)$ da banda de valência (BV) para a banda de condução (BC), deixando lacunas $\left(h^{+}\right)$na BV (Equação 1). ${ }^{120-122}$

Fotocatalisador + energia (luz) $\rightarrow h^{+}{ }_{B V}+e^{-}{ }_{B C}$

Os elétrons e as lacunas podem reagir com diferentes espécies, como por exemplo, moléculas de oxigênio $\left(\mathrm{O}_{2}\right)$ e água $\left(\mathrm{H}_{2} \mathrm{O}\right)$ adsorvidos na superfície do fotocatalisador para produzir radicais de superóxido $\left(\cdot \mathrm{O}_{2}^{-}\right)$e hidroxila $(\cdot \mathrm{OH})$, respectivamente (Equações 2-3). ${ }^{123-125}$ Dessa forma, esses radicais e também as lacunas são capazes de promover reações que podem viabilizar a mineralização do poluente orgânico (Equações 4-6). ${ }^{126-130}$

$\mathrm{O}_{2 \text { (ads) }}+e^{-}{ }_{B C} \rightarrow \cdot O_{2}$

$\mathrm{E}^{\mathrm{o}}$ redução $(\mathrm{eV})$ $-0,33(2)$

$\mathrm{H}_{2} \mathrm{O}_{\text {(ads) }}+h^{+}{ }_{B V} \rightarrow \cdot \mathrm{OH}+\mathrm{H}^{+}$

$h^{+}{ }_{B V}+$ poluente $\rightarrow$ produtos de degradação $+\mathrm{CO}_{2}+\mathrm{H}_{2} \mathrm{O}+$ minerais (4)

$\cdot \mathrm{O}_{2}^{-}+$poluente $\rightarrow$ produtos de degradação $+\mathrm{CO}_{2}+\mathrm{H}_{2} \mathrm{O}+$ minerais (5)

$\cdot \mathrm{OH}+$ poluente $\rightarrow$ produtos de degradação $+\mathrm{CO}_{2}+\mathrm{H}_{2} \mathrm{O}+$ minerais (6)

Nesse sentido, nanotubos de titanato de potássio $\left(\mathrm{K}_{2} \mathrm{Ti}_{6} \mathrm{O}_{3}\right)$ modificados por pontos quânticos de carbono ( $\mathrm{PQCs}$ ) foram aplicados na degradação do antibiótico Amoxicilina no estudo de Chen et al. ${ }^{103}$ Os nanotubos de $\mathrm{K}_{2} \mathrm{Ti}_{6} \mathrm{O}_{3}$ foram sintetizados pelo método hidrotérmico em solução alcalina de hidróxido de potássio $(\mathrm{KOH})$, a partir do precursor $\mathrm{TiO}_{2}$. O produto obtido, após 12 horas no tratamento hidrotérmico, foi adicionado a uma solução de PQCs e calcinados a $300{ }^{\circ} \mathrm{C}$ por 2 horas, obtendo assim o fotocatalisador modificado $\mathrm{PQCs} / \mathrm{K}_{2} \mathrm{Ti}_{6} \mathrm{O}_{3}$. Esse material apresentou menor energia de band gap, o que permitiu a esse catalisador degradar até 73,5\% de amoxicilina sob radiação visível e ainda se manteve estável após cinco ciclos de reuso.

Outro trabalho que investigou as propriedades fotocatalíticas dos titanatos de potássio foi o estudo de Xiong e Zhao. ${ }^{131}$ Eles reportaram a síntese de tetratitanato de potássio $\left(\mathrm{K}_{2} \mathrm{Ti}_{4} \mathrm{O}_{9}\right)$ modificado com sulfeto de cádmio (CdS) intercalado entre as lamelas do titanato, com o intuito de utilizá-lo na degradação do corante azul de metileno (MB) sob irradiação na faixa do visível. $\mathrm{O} \mathrm{K}_{2} \mathrm{Ti}_{4} \mathrm{O}_{9}$ foi obtido através da calcinação de carbonato de potássio e $\mathrm{TiO}_{2}$ a $960^{\circ} \mathrm{C}$ por 10 horas, e a intercalação do CdS entre as lamelas do titanatos foi realizada por um mecanismo de troca iônica em solução de $\mathrm{Cd}\left(\mathrm{NO}_{3}\right)_{2}$ sob agitação. A associação desses semicondutores é interessante, pois o CdS é um semicondutor ativo sob luz visível e capaz de gerar espécies reativas; porém, o CdS apresenta baixa estabilidade e alta taxa de recombinação. Assim, intercalá-lo nas lamelas do titanato pode estabilizar o material, além de diminuir a recombinação. Os autores concluíram que a modificação melhorou a atividade fotocatalítica na degradação do MB e garantiu boa estabilidade após quatro ciclos de reutilização.

Sehati e Entezari ${ }^{132}$ também realizaram a intercalação de CdS entre as camadas do $\mathrm{K}_{2} \mathrm{Ti}_{4} \mathrm{O}_{9}$, porém nesse estudo o ultrassom foi utilizado na etapa de intercalação para auxiliar na troca iônica. Primeiramente, o $\mathrm{K}_{2} \mathrm{Ti}_{4} \mathrm{O}_{9}$ teve seus íons de potássio substituídos por hidrogênio, com a utilização de uma solução de $\mathrm{HCl}$, obtendo-se $\mathrm{o}_{2} \mathrm{Ti}_{4} \mathrm{O}_{9}$ em camadas e, em seguida, realizou-se a intercalação do CdS, com o auxílio do ultrassom, utilizando uma solução de $\mathrm{Cd}\left(\mathrm{NO}_{3}\right)_{2}$. Na sequência, essa mistura foi calcinada a $400{ }^{\circ} \mathrm{C}$, por 2 horas, obtendo o $\mathrm{CdS} / \mathrm{Ti}_{4} \mathrm{O}_{9}$. Esse material foi avaliado em aplicações fotocatalíticas, na degradação do corante vermelho congo (VC), sob luz solar direta, em dias ensolarados e horários estipulados pelos autores. Os resultados indicaram que o fotocatalisador $\mathrm{CdS} / \mathrm{Ti}_{4} \mathrm{O}_{9}$ sintetizado apresentou atividade fotocatalítica e estabilidade melhoradas em comparação com o $\mathrm{CdS}$ e $\mathrm{K}_{2} \mathrm{Ti}_{4} \mathrm{O}_{9}$ separadamente. Esse desempenho se deve ao fato do espaço interlamelar do $\mathrm{CdS} / \mathrm{Ti}_{4} \mathrm{O}_{9}$ ser maior que o $\mathrm{K}_{2} \mathrm{Ti}_{4} \mathrm{O}_{9}$, permitindo maior penetração do corante resultando na maior fotodegradação. A associação desses dois materiais diminuiu a taxa de recombinação e a fotocorrosão do $\mathrm{CdS}$ que foi medida pela quantidade de $\mathrm{Cd}^{2+}$ liberada na solução, reduzindo 75,5\% em comparação com o CdS.

A aplicação de titanatos intercalados na degradação de corantes também foi estudada por Anto, Nethravathi e Rajamathi. ${ }^{133}$ Os autores relataram a intercalação, por troca iônica em meio aquoso, de n-alquilaminas com diferentes comprimentos de cadeia nas camadas de $\mathrm{K}_{2} \mathrm{Ti}_{4} \mathrm{O}_{9}$ e sua aplicação na degradação do corante MB sob radiação UV. Nesse estudo, os titanatos intercalados com a amina também foram submetidos a tratamento térmico a $110{ }^{\circ} \mathrm{C}$, sendo que os titanatos que antes apresentaram uma coloração branca, após o tratamento tornaram-se marrons. $\mathrm{O}$ material tratado termicamente apresentou atividade fotocatalítica superior ao $\mathrm{K}_{2} \mathrm{Ti}_{4} \mathrm{O}_{9}$ sem a intercalação. Além disso, os autores também relataram que os titanatos submetidos ao tratamento térmico com n-alquilaminas de cadeias maiores apresentaram atividade fotocatalítica maior sob radiação UV, se comparado com os materiais que tiveram intercalação com n-alquilaminas de cadeias menores. Os autores associaram essa melhora de atividade ao aumento do espaço entre as camadas, possibilitando melhor acesso às superfícies delas. A melhora da atividade fotocatalítica também está associada à melhor separação de cargas, devido à dopagem com nitrogênio.

A capacidade de adsorção do fotocatalisador também é uma característica importante, visto que a adsorção seletiva de uma molécula permite que a degradação do poluente seja mais eficiente. ${ }^{134}$ Nanofolhas de titanato protonado $\left(\mathrm{H}_{2} \mathrm{Ti}_{2} \mathrm{O}_{5} \cdot \mathrm{H}_{2} \mathrm{O}\right)$ foram usadas na fotodegradação de fármacos. Wu et al. ${ }^{127}$ sintetizaram esse material pelo método hidrotérmico. Nesse trabalho, as nanofolhas de $\mathrm{H}_{2} \mathrm{Ti}_{2} \mathrm{O}_{5} \cdot \mathrm{H}_{2} \mathrm{O}$ apresentaram atividade fotocatalítica para degradação do fármaco ciprofloxacina superior, se comparado ao $\mathrm{TiO}_{2}$. Os autores concluíram que essa atividade fotocatalítica superior está associada à capacidade de adsorção e também aos planos (010) muito expostos, pois tais planos apresentam uma estrutura de superfície similar aos planos (001) bastante reativos da fase anatase.

A adsorção de moléculas por nanotubos, para remoção de poluentes, foi investigada por Mohanty, Moulick e Maji, ${ }^{135}$ que sintetizaram nanotubos de titanato de sódio (TNTs) pelo método hidrotérmico com hidróxido de sódio $(\mathrm{NaOH})$ a $10 \mathrm{~mol} \mathrm{~L}^{-1} \mathrm{e} \mathrm{TiO}_{2}$ como precursor. Com o objetivo de promover a substituição dos átomos de sódio por hidrogênio, o material obtido, após a secagem, foi tratado com uma solução de $\mathrm{HCl}$, obtendo-se o fotocatalisador desejado que foi denominado por HTNT. Essa possiblidade de substituição é outra característica interessante dos titanatos. A capacidade adsortiva dos nanotubos (TNT e HTNT) e a viabilidade do processo de adsorção de corante cristal violeta $(\mathrm{CV})$ foram avaliadas a partir das isotermas de Langmuir, indicando uma cinética de pseudo-segunda ordem. O ponto de saturação de adsorção foi alcançado após 2 horas, onde a remoção máxima de CV obtida foi de aproximadamente $80 \%$. Esses dois materiais não apresentaram diferença quanto à eficiência na remoção 
do corante e sob radiação UV com comprimento de onda de 360 nm, onde obteve-se aproximadamente $95 \%$ de remoção do corante.

A taxa de adsorção de moléculas na superfície do fotocatalisador é influenciada, entre outras coisas, pela extensa área superficial específica e pelo tamanho dos poros. Nesse sentido, os autores Liu et al. ${ }^{136}$ avaliaram a eficiência fotocatalítica de titanatos de sódio sintetizados pelo método hidrotérmico na fotodegradação de corante azul de metileno sob luz UV. Os resultados indicaram que houve a degradação de aproximadamente $99 \%$ do corante, sendo a área de superfície específica e o alto volume de poros os principais fatores que influenciaram positivamente na eficiência fotocatalítica. Segundo os autores, essas características melhoram a atividade fotocatalítica do semicondutor, visto que quanto maior a área específica, mais poluente pode ser adsorvido e quanto maior o volume de poros, mais rapidamente ocorrerá a difusão dos produtos de reação.

Com o objetivo de tornar os nanotubos de $\mathrm{TiO}_{2}$ mais viáveis e ativos, sob radiação visível, vários estudos estão sendo realizados, como por exemplo, no trabalho de Backes et al ${ }^{137}$ Nesse trabalho foi realizada a sensibilização de nanotubos de $\mathrm{TiO}_{2}$ impregnando riboflavina (RF) na sua superfície. A sensibilização requer que a distância entre o sensibilizador e a superfície do semicondutor seja a menor possível e isso pode ser alcançado na síntese do material, por adsorção do sensibilizador à superfície do semicondutor. Assim, após a absorção do fóton e a excitação eletrônica, é possível a injeção de um elétron na $\mathrm{BC}$ do semicondutor, levando à formação de espécies radicais como o $\bullet_{2}^{-}$. Nesse trabalho, os nanotubos de $\mathrm{TiO}_{2}$ foram sintetizados pelo método de anodização, utilizando uma folha de Ti com uma tensão aplicada constante à temperatura ambiente, com um eletrólito contendo etilenoglicol e $\mathrm{NH}_{4} \mathrm{~F}$. Após a anodização, os nanotubos foram calcinados a $400{ }^{\circ} \mathrm{C}$ por 3 horas e imersos em solução de RF por 24 horas, para impregnação do sensibilizador. Os autores relataram que os nanotubos de $\mathrm{TiO}_{2}$ impregnados com riboflavina têm a capacidade de gerar oxigênio, uma propriedade bastante interessante, pois a degradação de poluentes orgânicos acontece em um ambiente aerado. A associação entre a riboflavina e os nanotubos de $\mathrm{TiO}_{2}$ beneficiou o processo fotocatalítico na degradação de diferentes corantes, pois permitiu a ativação do semicondutor sob luz visível, além de gerar preferencialmente oxigênio in situ que aumentou a eficiência de fotodegradação. Outro trabalho que avaliou a atividade fotocatalítica na degradação de corantes utilizando nanotubos de $\mathrm{TiO}_{2}$ modificados foi o de Sim et al., ${ }^{138}$ em que os nanotubos foram sintetizados pelo método de anodização e na sequência, houve a formação de uma heteroestrutura com o nitreto de carbono grafítico $\left(\mathrm{g}-\mathrm{C}_{3} \mathrm{~N}_{4}\right)$ para a degradação do corante MB sob luz visível.

\section{Fotorredução de dióxido de carbono $\left(\mathrm{CO}_{2}\right)$ com materiais lamelares à base de $\mathbf{T i}$}

Outra aplicação ambiental para os materiais lamelares de Ti é a fotorredução de dióxido de carbono $\left(\mathrm{CO}_{2}\right)$. Avaliando-se a termodinâmica da redução do $\mathrm{CO}_{2}$ em produtos de maior valor agregado, tais como metano, monóxido de carbono, metanol, entre outros, todas as reações possuem um potencial negativo (Equações 7-10), acarretando uma energia de Gibbs positiva. Logo, essas reações não ocorrem de forma espontânea, evidenciando a necessidade de energia (neste caso, fótons) e o uso de catalisadores para que a reação ocorra mais rapidamente. ${ }^{31,139-141}$

$$
\begin{aligned}
& \mathrm{CO}_{2}+2 e^{-}+2 \mathrm{H}^{+} \rightarrow \mathrm{CO}+\mathrm{H}_{2} \mathrm{O} \\
& \mathrm{CO}_{2}+2 e^{-}+2 \mathrm{H}^{+} \rightarrow \mathrm{HCOOH} \\
& \mathrm{CO}_{2}+6 e^{-}+6 \mathrm{H}^{+} \rightarrow \mathrm{CH}_{3} \mathrm{OH}+\mathrm{H}_{2} \mathrm{O} \\
& \mathrm{CO}_{2}+8 e^{-}+8 \mathrm{H}^{+} \rightarrow \mathrm{CH}_{4}+2 \mathrm{H}_{2} \mathrm{O}
\end{aligned}
$$$$
\mathrm{E}^{\mathrm{o}} \text { redução }(\mathrm{V})
$$

$-0,61 \quad(8)$
O mecanismo pelo qual ocorre a reação de fotorredução catalítica de $\mathrm{CO}_{2}$ ainda não está definitivamente esclarecido, pois existem ramificações que conduzem a diversos produtos ao mesmo tempo, existindo divergências entre os vários pesquisadores do assunto..$^{16,139-141}$

A Figura 6B esquematiza o mecanismo de fotorredução de $\mathrm{CO}_{2}$, utilizando a superfície de um semicondutor como catalisador, em uma interface sólido-liquido ou sólido-gás, e envolve a ativação do fotocatalisador, migração das cargas e a reação das cargas geradas com o $\mathrm{CO}_{2}$ adsorvido. Alguns desafios relacionados à baixa atividade, seletividade e estabilidade, e aos altos valores de band gap dos materiais fotocatalisadores ainda precisam ser superados para tornar esse processo viável para ampliação de sua aplicação. ${ }^{31}$

Devido às características dos materiais lamelares já citadas anteriormente, estes materiais se tornam promissores também para o processo de fotorredução do $\mathrm{CO}_{2}$ em diferentes produtos de valor agregado. Nestes sentido, a fotorredução de $\mathrm{CO}_{2}$ em gás metano $\left(\mathrm{CH}_{4}\right)$ foi investigada por Kar et al. ${ }^{142}$ utilizando-se nanotubos de $\mathrm{TiO}_{2}$ sintetizados pelo método de anodização eletroquímica em diferentes eletrólitos. Os nanotubos sintetizados também passaram por tratamento térmico de 3 horas a $450{ }^{\circ} \mathrm{C}$. Na sequência, os nanotubos foram submetidos a uma chama de gás propano de aproximadamente $750{ }^{\circ} \mathrm{C}$. Os resultados indicaram alta taxa de redução de $\mathrm{CO}_{2}$, pois os nanotubos sintetizados por meio aquoso apresentaram 156,5 $\mu \mathrm{mol}\left(\mathrm{g}_{\text {catalisador }} \mathrm{h}\right)^{-1}$ (rendimento por unidade de massa) na produção de metano sob luz solar simulada, sendo essa uma taxa de produção de $\mathrm{CH}_{4}$ alta, segundo os autores.

Em busca de melhorias na eficiência dos nanotubos de titanato de sódio (NTTs) na fotorredução de $\mathrm{CO}_{2}$ a $\mathrm{CH}_{4}$ sob luz solar simulada, Parayil et al. ${ }^{143}$ relataram a síntese com co-dopagem dos NTTs com carbono (C) e nitrogênio (N). Para a síntese dos NTTs foi utilizado o método hidrotérmico com $\mathrm{TiO}_{2}$ em pó misturado em uma solução de $\mathrm{NaOH}$ a $10 \mathrm{~mol} \mathrm{~L}^{-1}$. A co-dopagem com $\mathrm{C}$ e $\mathrm{N}$ foi realizada através da calcinação de uma mistura dos NTTs com a ureia à temperatura de $400{ }^{\circ} \mathrm{C}$ por 3 horas. Os autores relataram que o NTT co-dopado foi o que apresentou maior fotorredução de $\mathrm{CO}_{2}$, apresentando uma produção de $\mathrm{CH}_{4}$ de $9,75 \mu \mathrm{mol} / \mathrm{g}$.h. Esse resultado foi relacionado à maior área superficial dos nanotubos e à melhor adsorção da molécula de $\mathrm{CO}_{2}$ pelo NTT. A partir disso, os autores concluíram que a atividade fotocatalítica dos NTTs é proporcionada por diversos fatores, dentre eles, os íons sódio $\left(\mathrm{Na}^{+}\right)$intercalados entre as camadas que promovem a adsorção de $\mathrm{CO}_{2}$ e a co-dopagem que permite a ativação do fotocatalisador sob luz solar simulada.

Outro estudo com o objetivo de promover a redução catalítica de $\mathrm{CO}_{2}$ foi conduzido por Li et al. ${ }^{144}$ Eles relataram a síntese de filmes de nanotubos de $\mathrm{TiO}_{2}$ com óxido de magnésio $(\mathrm{MgO})$ em camadas finas e amorfas localizadas na superfície dos nanotubos. A síntese procedeu pelo método hidrotérmico, com solução de $\mathrm{NaOH}$ $10 \mathrm{~mol} \mathrm{~L}^{-1} \mathrm{e}$ troca iônica, lavando os nanotubos com $\mathrm{HCl}$ formando ácido titânico (TAN). Os filmes de TAN foram imersos em soluções de $\mathrm{Mg}\left(\mathrm{NO}_{3}\right)_{2}$ e calcinados a $500{ }^{\circ} \mathrm{C}$, por 4 horas, obtendo os filmes de nanotubos de $\mathrm{MgO} / \mathrm{TiO}_{2}$. A heteroestrutura apresentou atividade fotocatalítica superior se comparado ao $\mathrm{TiO}_{2}$ puro. Os autores também modificaram os filmes com platina $(\mathrm{Pt})$, o que melhorou ainda mais a atividade fotocatalítica do fotocatalisador, obtendo taxas de produção de $\mathrm{CH}_{4}$ elevadas de aproximadamente $100,22 \mathrm{ppm} / \mathrm{h} \mathrm{cm}^{2}$. Os resultados indicaram que o $\mathrm{MgO}$ foi importante para manter a estrutura dos nanotubos e o Pt foi importante para aumentar a atividade fotocatalítica e melhorar a separação entre os elétrons e os buracos.

Filmes de TAN também foram utilizados por Bi et al. ${ }^{145}$ como material precursor para fabricar um filme de heterojunção $\mathrm{TiO}_{2} / \mathrm{SrTiO}_{3}$ pelo método hidrotérmico. As caracterizações indicaram que nanocubos de $\mathrm{SrTiO}_{3}$ se dispersaram uniformemente nos 
nanotubos de $\mathrm{TiO}_{2}$. A heterojunção $\mathrm{TiO}_{2} / \mathrm{SrTiO}_{3}$, obtida em 1 hora de tratamento hidrotérmico, apresentou a melhor atividade para fotorredução de $\mathrm{CO}_{2}$. A eficiência de fotoconversão de $\mathrm{CO}_{2}$ em $\mathrm{CH}_{4}$ melhorou, notavelmente, depois que as nanopartículas "sequestradoras" de elétrons (platina-Pt e paládio-Pd) foram carregadas na superfície, sendo a maior taxa de produção fotocatalítica de $\mathrm{CH}_{4} 20,83 \mathrm{ppm} / \mathrm{h}$ $\mathrm{cm}^{2}$ com o metal Pd na superfície da heterojunção. Além disso, a seletividade do produto de fotorredução de $\mathrm{CO}_{2}$ também aumentou quando o Pd atuou como co-catalisador no filme de heterojunção $\mathrm{TiO}_{2} / \mathrm{SrTiO}_{3}$.

Outra heteroestrutura com nanotubos de $\mathrm{TiO}_{2}$ aplicada na fotorredução de $\mathrm{CO}_{2}$ foi apresentada no trabalho de Razali, e Yusoff, ${ }^{146}$ onde foi sintetizada a heteroestrutura de óxido de cobre $(\mathrm{CuO})$ com os nanotubos pelo método hidrotérmico. A junção foi benéfica para a fotorredução de $\mathrm{CO}_{2}$, pois foi possível combinar a característica de alta área superficial dos nanotubos de $\mathrm{TiO}_{2}$ com a característica do $\mathrm{CuO}$ de apresentar posições de banda que possibilitam a fotorredução de $\mathrm{CO}_{2}$, além de ser um semicondutor relativamente barato. Através do teste fotocatalítico, os autores relataram a melhora da atividade fotocatalítica da junção, se comparada aos semicondutores puros, pois em um período de 150 minutos a junção possibilitou a conversão de $100 \%$ de $\mathrm{CO}_{2}$, enquanto que os semicondutores puros de $\mathrm{TiO}_{2} \mathrm{e}$ $\mathrm{CuO}$, em um período de 180 minutos, converteram $72,2 \%$ e 44,8\%, respectivamente. Os autores relataram que a junção formada entre os dois semicondutores melhorou a atividade fotocatalítica para redução de $\mathrm{CO}_{2}$, pois os semicondutores formaram uma junção $\mathrm{p}$-n que melhorou a separação das cargas fotogeradas e diminuiu o efeito de recombinação.

Outra vertente da fotorredução, utilizando-se semicondutores é a redução de íons metálicos tóxicos em efluentes. Embora pouco explorada, a redução fotocatalítica de metais usando os catalisadores semicondutores é considerada uma técnica promissora no tratamento de águas residuais. ${ }^{31}$ Liu et al. ${ }^{147}$ aplicaram nanotubos porosos de $\mathrm{TiO}_{2}$ (PTNTs) sensibilizadas com corante vermelho do congo (VC) no processo de fotorredução de $\mathrm{Cr}$ (VI). Os PTNTs foram impregnados com corante $\mathrm{VC}$ e aplicados como um fotocatalisador para a redução induzida pela luz visível de $\mathrm{Cr}$ (VI). O bom desempenho fotocatalítico dos nanotubos porosos de $\mathrm{TiO}_{2}$ foi associado à sua estrutura em nanotubos e sua atividade fotocatalítica sob luz visível foi proporcionada pelo corante, sendo que o VC, mesmo sendo um corante, não ocasionou nova poluição. A redução de metais pesados ocorre quando os elétrons migram para a $\mathrm{BC}$ do semicondutor e se tornam elétrons livres que podem reduzir os íons de cromo (VI) na solução (Equação 11). Assim, o cromo trivalente ( $\mathrm{Cr}$ (III)) precipita na solução, tornando-se fácil de ser removido do meio e apresenta baixa toxicidade, sendo um micronutriente essencial para o corpo humano, em pequenas quantidades. ${ }^{148,149}$ Desse modo, os autores concluíram que os nanotubos porosos de $\mathrm{TiO}_{2}$ podem ser utilizados como fotocatalisadores em remediação ambiental, através da fotorredução de Cr (VI) sob luz visível.

$\mathrm{E}^{\mathrm{o}}$ redução $(\mathrm{V}) /$ meio ácido

$$
\mathrm{HCrO}_{4(a q)}^{-}+7 \mathrm{H}_{a q}^{+}+3 e_{\mathrm{aq}}^{-} \leftrightarrow \downarrow \mathrm{Cr}^{+3}+4 \mathrm{H}_{2} \mathrm{O}+1,35
$$

\section{Produção de hidrogênio com materiais lamelares de Ti}

Desde o trabalho de Fujishima e Honda em $1972^{150}$ de geração de energia utilizando semicondutores no processo de fotocatálise heterogênea, muitos trabalhos focaram em desenvolver essa tecnologia e aplica-la em escalas maiores na geração de $\mathrm{H}_{2}$. A quebra da molécula de água requer uma alta energia de Gibbs de aproximadamente $237,46 \mathrm{~kJ} \mathrm{~mol}^{-1}$, logo se faz necessário um fotocatalisador eficiente na captação de energia na forma de fótons para melhores rendimentos reacionais e acelerar a reação. ${ }^{87} \mathrm{~A}$ produção de $\mathrm{H}_{2(\mathrm{~g})}$ via water spliting, é um processo em que a luz incidente promove a geração de lacunas no eletrodo. A quebra da água é ilustrada na Figura 6C utilizando material lamelar à base de Ti como fotoanodo e Pt como cátodo ${ }^{87} \mathrm{As}$ lacunas oxidam a água para formar $\mathrm{O}_{2}$ na superfície do semicondutor, enquanto que os elétrons fotogerados reduzem os íons $\mathrm{H}^{+} \mathrm{e}$ formam $\mathrm{H}_{2}$ em um contra eletrodo (Equação 12-13). ${ }^{87,151}$

$$
\begin{aligned}
& \boldsymbol{H}_{2} \boldsymbol{O}+2 \boldsymbol{h}_{B V}^{+} \rightarrow \frac{1}{2} \boldsymbol{O}_{2}+2 \boldsymbol{H}^{+} \\
& \mathrm{E}^{\mathrm{o}} \text { redução }(\mathrm{V}) \\
& -1,23 \text { (12) } \\
& 2 H^{+}+2 e_{B C}^{-} \rightarrow \uparrow H_{2}
\end{aligned}
$$

Sun, Wang e Yan ${ }^{152}$ aplicaram nanotubos de $\mathrm{TiO}_{2}$ obtidos por anodização eletroquímica na produção de hidrogênio pelo processo de water splitting sob luz visível. Foram sintetizadas diferentes amostras de nanotubos variando-se o tempo de anodização entre 10, 30, 60 e 120 minutos, Quanto aos nanotubos sintetizados por um período de 60 min de anodização, apresentaram taxa de produção de hidrogênio de $2,32 \mathrm{~mL} \mathrm{~h}^{-1} \mathrm{~cm}^{-2}$. Os autores relataram que esses nanotubos apresentaram boa estabilidade após um teste de 12 horas de produção de hidrogênio.

O uso de nanopartículas de Pt é muito citada na literatura por promover o avanço da produção de $\mathrm{H}_{2} \cdot{ }^{153,154}$ Jitputti, Suzuki e Yoshikawa ${ }^{101}$ sintetizaram nanofios de $\mathrm{TiO}_{2}$ pelo método de síntese hidrotérmico em solução alcalina de $\mathrm{NaOH} 10 \mathrm{~mol} \mathrm{~L}^{-1}$ e estudaram a sua utilização na produção de $\mathrm{H}_{2}$ pelo processo water spliting. Além disso, eles depositaram Pt em sua superfície, o que provocou a diminuição da taxa de recombinação e o aumento na eficiência para a produção de $\mathrm{H}_{2}$ que atingiu o máximo de $205 \mu \mathrm{mol} \mathrm{min}{ }^{-1}$ após 30 min de irradiação UV. Outro trabalho que avaliou o uso de co-catalisador metálico em estruturas lamelares de Ti para produção de $\mathrm{H}_{2}$ foi o Yu et al. ${ }^{155}$ Os autores relataram a síntese do titanato de potássio $\left(\mathrm{K}_{2} \mathrm{Ti}_{8} \mathrm{O}_{17}\right)$ modificado pelo co-catalisador Pt. Esse titanato de estrutura em forma de túnel estável se mostrou eficiente produzindo $\mathrm{H}_{2}$ a uma taxa de $390,17 \mathrm{mmol}$ (mol de catalisador) ${ }^{-1} \mathrm{~h}^{-1}$. O estudo sugeriu que a eficiência desse material na evolução de $\mathrm{H}_{2}$ se deve ao tratamento hidrotérmico que introduziu grande quantidade de grupos hidroxilas na superfície, provocando melhor separação das cargas fotogeradas.

Nos estudos de Shibata et al..$^{50}$ os titanatos lamelares $\mathrm{Na}_{2} \mathrm{Ti}_{3} \mathrm{O}_{7}$, $\mathrm{K}_{2} \mathrm{Ti}_{2} \mathrm{O}_{5}, \mathrm{~K}_{2} \mathrm{Ti}_{4} \mathrm{O}_{9}$ e $\mathrm{K}_{2} \mathrm{Ti}_{6} \mathrm{O}_{13}$ foram utilizados na produção de $\mathrm{H}_{2(\mathrm{~g})}$, sendo as estruturas lamelares desses compostos confirmadas por DRX e estáveis em ampla faixa de temperatura. Acima de $623 \mathrm{~K}$ observaram-se mudanças na estrutura cristalina e, em $1123 \mathrm{~K}$, o material antes lamelar muda completamente sua estrutura cristalina para $\mathrm{TiO}_{2}$ na fase anatase. A atividade fotocatalítica para a produção de $\mathrm{H}_{2(\mathrm{~g})}$ dos titanatos foi comparada com a atividade fotocatalítica do $\mathrm{TiO}_{2}$ na fase anatase e verificou-se que os titanatos apresentaram atividade fotocatalítica melhor do que o $\mathrm{TiO}_{2}$. Nesse estudo também foi analisada a atividade fotocatalítica dos titanatos modificados pela deposição da $\mathrm{Pt}$, os quais apresentaram atividade fotocatalítica superior em comparação com suas formas originais atingindo o máximo de produção $110 \mu \mathrm{mol} \mathrm{min}{ }^{-1}$ com o fotocatalisador $\mathrm{K}_{2} \mathrm{Ti}_{2} \mathrm{O}_{5}$ com Pt depositada em sua superfície.

A fotogeração de $\mathrm{H}_{2(\mathrm{~g})}$ também foi investigada por Feil et al. ${ }^{156}$ utilizando-se nanotubos de $\mathrm{TiO}_{2}$ impregnados com nanopartículas (NPs) de ouro (Au). Esse material foi sintetizado por oxidação anódica de folhas de titânio metálico e usando-se diferentes concentrações de $\mathrm{HAuCl}_{4}$. Posteriormente, os nanotubos foram calcinados para cristalizar o filme de $\mathrm{TiO}_{2}$. Os autores relataram uma melhora de $30 \%$ na produção de hidrogênio, utilizando os nanotubos modificados em relação aos nanotubos livres de $\mathrm{Au}$, sob as mesmas condições de 
iluminação. Além disso, eles concluíram que a concentração dessas NPs de Au influenciava diretamente na produção de gás hidrogênio. Assim, fica evidente que muitos trabalhos utilizam metais nobres $(\mathrm{Au}$ e $\mathrm{Pt}$ ) como co-catalisadores impregnados nas superfícies dos materiais lamelares de titânio, para aumentar a eficiência fotocatalítica na produção de hidrogênio.

Resultados significativos já foram obtidos nos estudos de Liu et al. ${ }^{157}$ utilizando-se uma heteroestrutura composta por $\mathrm{TiO}_{2} \mathrm{e}$ sulfeto de molibdênio $\left(\mathrm{MoS}_{2}\right)$. Este material foi obtido pelo método hidrotérmico com o uso de molibdato de sódio $\left(\mathrm{Na}_{2} \mathrm{MoO}_{4} \cdot 2 \mathrm{H}_{2} \mathrm{O}\right)$ e nanofibras de $\mathrm{TiO}_{2}$. Essa heteroestrutura apresentou uma taxa de produção de hidrogênio de $1,68 \mathrm{mmol} \mathrm{h}^{-1} \mathrm{~g}^{-1}$ e não houve perda na eficiência após 6 ciclos de reuso evidenciando ser estável. Em uma abordagem mais recente de Cao et al. ${ }^{158}$ esse mesmo material foi obtido pela combinação dos métodos de anodização e hidrotérmico. A heterojunção de $\mathrm{TiO}_{2} / \mathrm{MoS}_{2}$ sintetizada apresentou grande quantidade de sítios ativos, devido à pequena espessura e enrugamento das nanofolhas de $\mathrm{MoS}_{2}$. Os autores aplicaram esse material na degradação de corantes, obtendo $100 \%$ de degradação do corante azul de metileno e na produção de hidrogênio chegando a uma produção de 900,9 $\mu \mathrm{mol}$ após 210 minutos de irradiação $(0,257 \mathrm{mmol} / \mathrm{h})$.

Outro fotoanodo isento de metal nobre, estudado na reação de divisão de água sob radiação visível, foi o $\mathrm{BiVO}_{4} / \mathrm{TiO}_{2}$. A deposição de nanopartículas de $\mathrm{BiVO}_{4}$ em nanotubos de $\mathrm{TiO}_{2}$ levou à geração de um fotoanodo heteroestruturado promissor na quebra da água para geração de $\mathrm{H}_{2}$. No trabalho de Perini et al. ${ }^{159}$ os nanotubos de $\mathrm{TiO}_{2}$ foram sintetizados por anodização e as nanopartículas de $\mathrm{BiVO}_{4}$ por método hidrotérmico. A formação da heteroestrutura foi investigada por dois métodos: revestimento por rotação (spin coating) e secagem por pulverização (spray dry). A amostra preparada pela deposição spray dry obteve resultados inferiores que o spin coating, evidenciando assim que o tipo de deposição pode aumentar o contato eletrônico entre esses materiais, minimizando os centros de recombinação de carga e aumentando a eficiência fotocatalítica.

\section{Aplicações de Inibição microbiana com materiais lamelares de Ti}

Os fotocatalisadores semicondutores não são apenas considerados como tecnologia verde para degradar poluentes orgânicos e gerar energia renovável, mas também estão emergindo como material antimicrobiano. Bactérias como Escherichia coli (E. coli) gramnegativa e Staphylococcus aureus ( $S$. aureus) gram-positiva são resistentes e podem sobreviver em várias superfícies sendo um problema mundial na medicina, devido às infecções resistentes. Cada tipo de microorganismo responde à inativação fotocatalítica de forma singular, entretanto evidências publicadas por Cho et al. ${ }^{160}$ e Jiang et al. ${ }^{161}$ afirmam que os radicais gerados após a irradiação do semicondutor são responsáveis pelo mecanismo de inativação. Nesses casos de inativação, os radicais afetam a estrutura da membrana plasmática fosfolipídica dos microorganismos causando danos, como perda do material celular (Figura 6D). ${ }^{162}$

Os materiais antimicrobianos utilizando-se nanopartículas como prata $(\mathrm{Ag})$ e cobre $(\mathrm{Cu})$ têm se desenvolvido, entretanto, a $\mathrm{Ag}$ apresenta baixa viabilidade econômica e o $\mathrm{Cu}$ não apresenta alta eficiência. No trabalho de Joshi et al. ${ }^{163}$ nanotubos dopados com Ag e $\mathrm{Cu}(\mathrm{Ag} / \mathrm{Cu}-\mathrm{NTT})$ foram utilizados em um processo fotocatalítico para inativação de bactérias $S$. aureus. Os nanotubos foram sintetizados pelo método hidrotérmico alcalino auxiliado por micro-ondas, sendo que as modificações com $\mathrm{Ag}$ e $\mathrm{Cu}$ foram realizadas pelo processo de fotodeposição utilizando $\mathrm{AgNO}_{3}$ e $\mathrm{CuSO}_{4}$ como precursores. Os autores justificam que a escolha de titanatos, carregados com Ag e $\mathrm{Cu}$, se deve à alta área de superfície dos titanatos e o carregamento de
$\mathrm{Cu}$ junto com as nanopartículas de $\mathrm{Ag}$ pode ser vantajoso do ponto de vista econômico ao minimizar a quantidade de Ag necessária. Assim, a modificação dos nanotubos com os metais diminuiu o processo de recombinação, além de aumentar a absorção da luz visível. Ao lado da toxicidade do $\mathrm{Ag}$ e do $\mathrm{Cu}$ para as bactérias, a formação de espécies reativas de oxigênio (ROS), como radical ânion superóxido $\left({ }^{\circ} \mathrm{O}_{2}^{-}\right)$, é outro fator responsável pela inativação das bactérias. A inativação quase total da bactéria $S$. aureus foi possível após 90 minutos utilizando $\mathrm{Ag} / \mathrm{Cu}-\mathrm{NTT}$ sob irradiação na faixa do visível e o mecanismo proposto sugere que esse material tem a capacidade de produzir alto estresse oxidativo, devido às ROS que degradam a parede celular, proteínas, lipídios, aminoácidos, carboidratos e DNA. Além disso, os íons $\mathrm{Ag}^{+}$e $\mathrm{Cu}^{2+}$ liberados na superfície e no interior da bactéria danificam a parede celular e as organelas celulares, respectivamente, causando a morte celular.

Outro trabalho que aplicou nanotubos de $\mathrm{TiO}_{2}$ na inativação de bactérias $E$. coli e $S$. aureus foi apresentado por Podporska-Carrol et al. ${ }^{164}$ Eles sintetizaram nanotubos de $\mathrm{TiO}_{2}$ por um método de anodização eletroquímica e compararam a eficiência de inativação com $\mathrm{TiO}_{2}$ referência comercial (Evonic-Degussa P25). Os autores concluíram que os nanotubos sintetizados apresentaram uma alta atividade fotocatalítica na inativação desses microorganismos, pois, sob luz UV, em um período de 24 horas, houve a inativação de $97,53 \%$ e $99,94 \%$ de E. coli e $S$. aureus, respectivamente. Esses resultados indicam que a arquitetura e as propriedades físico-químicas dos nanotubos de $\mathrm{TiO}_{2}$ desempenham um papel significativo na atividade antibacteriana.

Hajjaji et al. ${ }^{165}$ sintetizaram nanotubos de $\mathrm{TiO}_{2}$ (dopados com Ag) pelo método de anodização e testaram sua atividade fotocatalítica na inativação da bactéria $E$. coli sob irradiação com luz na região do visível. Foram sintetizadas diferentes amostras de nanotubos de $\mathrm{TiO}_{2}$ pelo método de anodização utilizando diferentes potenciais de anodização em um eletrólito composto por etilenoglicol, água e $\mathrm{NH}_{4} \mathrm{~F}$. O objetivo desse estudo foi analisar os efeitos do diâmetro dos nanotubos em sua atividade fotocatalítica. Os nanotubos de $\mathrm{TiO}_{2}$ decorados com Ag, sintetizados com os potenciais de anodização de 60 e 70 V, apresentaram diâmetros maiores e melhores desempenhos, pois em um período de 90 minutos foi possível a inativação de 99,99\% da bactéria. Os autores associaram esse resultado ao fato do aumento da cristalinidade dos nanotubos, o que reduz os defeitos superficiais nesses materiais.

Outro material lamelar similar ao sintetizado por Hajjaji foi investigado por Patrón-soberano et al. ${ }^{166}$ Nanotubos de titanato unidimensional $\left(\mathrm{H}_{2} \mathrm{Ti}_{2} \mathrm{O}_{5} \cdot \mathrm{H}_{2} \mathrm{O}\right)$ funcionalizados com nanopartículas de $\mathrm{Ag}$, obtidos pelo método hidrotérmico, exibiram uma capacidade antibacteriana de longo prazo para inativar e prevenir a adesão bacteriana do agente patogênico $E$. coli. Os autores atribuíram essa eficiência à morfologia dos nanotubos de titanato e a integridade da membrana das bactérias foi danificada de forma irreversível, devido ao estresse oxidativo causado pelas espécies reativas de oxigênio.

\section{CONSIDERAÇÕES FINAIS}

Os materiais lamelares são promissores para diferentes aplicações, principalmente por apresentarem elevada área superficial específica e a capacidade de intercalação de diferentes espécies. Com relação à obtenção destes materiais, a maioria dos trabalhos da literatura sobre a síntese de materiais lamelares de Ti em pó faz uso do método hidrotérmico altamente alcalino, enquanto que a obtenção de filmes ocorre predominantemente pela anodização de placas de Ti com posterior tratamento térmico. Vários parâmetros de síntese podem ser alterados visando a melhoria de propriedades ópticas e de superfície, assim como pós-tratamentos que normalmente são utilizados para se melhorar a cristalinidade e estabilidade. Uma análise do cenário atual 
e das perspectivas futuras sugere que, apesar do grande potencial, os materiais lamelares de Ti são comparativamente pouco utilizados em processos fotocatalíticos, o que demonstra que esse é um campo de estudo ainda pouco explorado. Ainda são necessários mais estudos sobre o desenvolvimento de rotas de síntese mais simples e suaves que possibilitem a obtenção do material na forma mais estável e eficiente, além de se aprofundar na avaliação de alternativas para a melhoria das suas propriedades fotocatalíticas, visando especialmente aplicações em larga escala. Para melhorar a eficiência, os novos estudos devem focar principalmente na associação entre diferentes materiais, em que os materiais lamelares podem contribuir principalmente com a elevada área superficial. Além disso, a associação com semicondutores com menores energias de band gap pode promover a fotoativação desses materiais na região do visível, além de melhorar a separação das cargas fotogeradas.

\section{AGRADECIMENTOS}

Os autores agradecem às agências financiadoras: Conselho Nacional de Desenvolvimento Científico e Tecnológico (CNPq), Fundação de Amparo à Pesquisa do Estado de Minas Gerais (FAPEMIG) e Universidade Federal dos Vales do Jequitinhonha e Mucuri (UFVJM), pelo apoio financeiro na concessão das bolsas.

\section{REFERÊNCIAS}

1. Adeyemi, J. O.; Ajiboye, T.; Onwudiwe, D. C.; Water Air Soil Pollut. 2021, 232, 1 .

2. Dupont, J.; Quim. Nova. 2000, 23, 825.

3. Melin, V.; Salgado, P.; Thiam, A.; Henriquez, A.; Yanez, J.; Salazar, C.; Mansilla, H. D.; Chemosphere. 2021, 274, 129683.

4. Wiest, L.; Gosset, A.; Fildier, A.; Libert, C.; Herve, M.; Silbeud, E.; Giroud, B.; Vulliet, E.; Bastide, T.; Polome, P.; Perrodin, Y.; Sci. Total Environ. 2021, 774, 145779.

5. Queiros, V.; Azeiteiro, U. M.; Amadeu, M.; J. Hazard. Mater. 2021, 412, 125028.

6. Dhangar, K.; Kumar, M.; Sci. Total Environ. 2020, 738, 140320.

7. https://www.poder360.com.br/governo/liberacao-de-agrotoxicos-bateunovo-recorde-em-2020-no-5o-ano-de-alta, acessada em janeiro 2022.

8. https://agenciabrasil.ebc.com.br/internacional/noticia/2021-04/cupulado-clima-guterres-defende-acao-imediata-dos-lideres-mundiais, acessada em janeiro 2022.

9. https://news.un.org/pt/story/2021/04/1748452, acessada em janeiro 2022.

10. Antonopoulou, M.; Kosma, C.; Albanis, T.; Konstantinou, L.; Sci. Total Environ. 2021, 765, 144163.

11. Coha, ; Farinelli , G.; Tirafe, A.; Minella , M.; Vione, D.; Chem. Eng. J. 2021, 414, 128668.

12. Chen, X.; Zhou, J.; Chen , Y.; Zhou, Y.; Ding, L.; Liang, H.; Li, X.; Process Saf. Environ. Prot.. 2021, 145, 364.

13. Silva, G. T. S. T.; Carvalho, K. T. G.; Lopes, O. F.; Gomes, E. S.; Malagutti, A. R.; Mastelaro, V. R.; Ribeiro, C.; Mourão, H. A. J. L.; Chem. Cat. Chem. 2017, 19, 3795.

14. Nogueira, R. F. P.; Jardim, W. F.; Quim. Nova 1998, 21, 69.

15. Mourão, H. A. J. L.; JR. Avansi, ; Oliveira, J. E.; Firmiano, E. S.; Ribeiro, C.; Sci. Adv. Mater. 2013, 5, 1.

16. Xiong, J.; Song, P.; Di, J.; LI, H.; Appl. Catal., B 2019, 256, 117788 .

17. Hashimoto, K.; Irie, H.; Fujishima, A.; Jpn. J. Appl. Phys. 2005, 44, 8269.

18. Xia, X. H.; Liang, Y.; Wang, Z.; Fan, J.; Luo, Y. S.; Jia, Z. J.; Mater. Res. Bull. 2008, 43, 2187.

19. Roy, P.; Berger, S.; Schmuki, P.; Angew. Chem., Int. Ed. 2011, 50, 2904.

20. Keidel, E.; Farben-Zeitung 1929, 34, 1242.
21. Kato, S.; Mashio, F.; Abtr. Book Annu Meet Chemical Society of Japan. 1956, 223.

22. Zhang, X.; Jin, M.; Liu, Z.; Nishimoto, S.; Saito, H.; Murakami, T.; Fujishima, A.; Langmuir 2006, 22, 9477.

23. Nakata, K.; Fujishima, A.; J. Photochem. Photobiol., C 2012, 13, 169.

24. Henderson, M. A. Surf. Sci. Rep. 2011, 66, 185.

25. Gopinath, K. P.; Madhav, N. V.; Krishnan, A.; Malolan, R.; Rangarajan, G.; J. Environ. Manage. 2020, 270, 110906.

26. Nakata, K.; Ochiai, T.; Murakami, T.; Fujishima, A.; Electrochim. Acta 2012, 84, 103.

27. Katal, R.; Masudy-Panah, S.; Tanhaei, M.; Farahani, M. H. D. A.; Jiangyong, H.; Chem. Eng. J.. 2020, 384, 123384.

28. Gratzel, M.; Rotzinger, F. P.; Chem. Phys. Lett. 1985, 118, 474.

29. Bian, Z.; Zhu, J.; Li, H.; J. Photochem. Photobiol., C 2016, 28, 72.

30. Ziolli , R. L.; Jardim , W. F.; Quim. Nova 1998, 21, 319.

31. Bueno, R. T.; Lopes, O. F.; Carvalho, K. T. G.; Ribeiro, C.; Mourão, H. A. J. L.; Quim. Nova 2019, 42.

32. Mourão, H. A. J. L.; Medonça, V. R.; Malagutti, A. R.; Ribeiro, C.; Quim. Nova 2009, 32, 2181.

33. Xiao, X.; Miao, J.; Tao, H. B.; Hung, -F.; Wang, -Y.; Yang, H. B.; Liu, B.; Int. Mater. Rev. 2015, 11, 2115.

34. Li, J.; Zhao, Y.; Xia, M.; An, H.; Bai, H.; Wei, J.; Yang, B.; Yang, G.; Appl. Catal., B 2020, 261, 118244.

35. Hanna, S.; Baudys, M.; Krbal, M.; Zazpe, R.; Prikry, J.; Krysa, J.; Macak, J. M.; Electrochem. Commun. 2018, 97, 91.

36. Sreekantan, S.; Hazan, R.; Lockman, Z.; Thin Solid Films 2009, 518, 16.

37. Kapusuz, D.; Y. Kalay, E.; Park, J.; Ozturk, A.; Journal of Ceramic Processing Research 2015, 16, 291.

38. Barbé, C. J.; Arendse, F.; Comte, P.; Jirousek, M.; Lenzmann, F.; Shklover, V.; Grätzel, M.; J. Am. Ceram. Soc. 1997, 80, 3157.

39. Pires, A. L. R.; Bierhalz, A. C. K.; Moraes, Â. M.; Quim. Nova 2015, $38,957$.

40. Lou, S.; Zhao, Y.; Wang, J.; Yin, G.; Du, C.; Sun, X.; Small 2019, 15, 1904740

41. Costa, A. C. F. M.; Vilar, M. A.; Lira, H. L.; Kiminami, R. H. G. A.; Gama, L.; Cerâmica 2006, 52, 255.

42. Chiba, K.; Kijima, N.; Takahashi, Y.; Idemoto, Y.; Akimoto, J.; Solid State Ionics 2008, 178, 1725

43. Catti, M.; Pinus, I.; Scherillo, A.; J. Solid State Chem. 2013, 205, 64.

44. Silva, F. L. R.; Righi, A.; Vib. Spectrosc. 2017, 88, 77.

45. Sasaki, T.; Komatsu, Y.; Fujiki, Y.; Mat. Res. Bull. 1987, 22, 1321.

46. Kim, D. H.; Jang, J. S.; Han, S. S.; Lee, K. S.; Choi, S. H.; Umar, A.; Lee, J. W.; Shin, D. W.; Myung, S. T.; Lee, J. S.; Kim, S. J.; Sun, Y. K.; Lee, K. S.; J. Phys. Chem. C 2009, 113, 14034.

47. Nunes, L. M.; Airoldi, C.; Quím. Nova. 2001, 24, 799.

48. Schoonheydt, R. A.; Pinnavaia, T.; Lagaly, G.; Gangas, N.; Pure Appl. Chem. 1999, 71, 2367.

49. Kudo, A.; Kondo, T.; J. Mat. Chem. 1997, 777.

50. Shibata, M.; Kudo, A.; Tanaka, A.; Domen, K.; Maruya, K.; Onishi, T.; Chem. Lett. 1987, 16, 1017.

51. Papp, S.; Kõrösi, L.; Meynem, V.; Cool, P.; Vansant, E.; Dékány, I.; J. Solid State Chem. 2005, 178, 1614.

52. Wang, Q.; Guo, Z.; Chung, J. S.; Mater. Res. Bull. 2009, 44, 1973.

53. Iijima, S.; Nature 1991, 354, 56.

54. Marques, T. M. F.; Lima, C. L. L.; Sacilloti, M.; Fujisawa, K.; Lopez, N. P.; Terrones, M.; Silva, E. N.; Ferreira, O. P.; Viana, B. C.; J. Nanomater. 2017, 2017, 1.

55. Liu, H.; Yang, D.; Waclawik, E. R.; Ke, X.; Zheng, Z.; Zhu, H.; Frost, R. L. A.; J. Raman Spectrosc. 2010, 41, 1792.

56. Zhang, W.; Wang, Z.; Liu, Y.; Feng, J.; Han, J.; YAN, W.; Sci. Total Environ. 2021, 771, 144800.

57. Sun, X.; LI, Y.; Chem. Eur. J. 2003, 9, 2229.

58. Gleiter, H.; Acta Mater. 2000, 48, 1. 
59. Camposeco, R.; Castillo, S.; Mejia-Centeno, I.; Navarrete, J.; Gomez, R.; Mater. Charact. 2014, 90, 113.

60. Yang, D.; Liu, H.; Liu, L.; Sarina, S.; Zheng, Z.; Zhu, H.; Nanoscale 2013, 5, 11011.

61. Pang, Y. L.; Lim, S.; Ong, H. C.; Choong, W. T.; Appl. Catal., A 2014, 481, 127.

62. Bavykin, D. V.; Parmon, V. N.; Lapkin, A. A.; Walsh, F. C.; J. Mater. Chem. 2004, 14, 3370.

63. Huang, J.; Cao, Y.; Huang, Q.; He, H.; Liu, Y.; Guo, W.; Hong, M.; Cryst. Growth Des. 2009, 9, 3632.

64. Yang, K.; Yang, L.; Ai, C. Z.; Wang, Z.; Lin, S. W.; Chin. Phys. B 2019, 28, 103102 .

65. Zhang, L. Y.; Han, Y. L.; Yang, J. J.; Deng, S. L.; Wang, B. Y.; Appl. Surf. Sci. 2021, 546, 149089.

66. An, Y.; Wang, D.; Wu, C.; Phys. E 2014, 60, 210.

67. Chen, J.; Yang, L.; Fang, S.; Tang, Y.; Electrochim. Acta 2010, 55, 6596.

68. Nakahira, A.; Kubo, T.; Numako, C.; Appl. Mater. Interfaces 2010, 2 , 2611.

69. Morgan, D. L.; Triani, G.; Blackford, M. G.; Raftery, N. A.; Frost, R. L.; Waclawik, E. R.; J. Mater. Sci. 2011, 46, 548.

70. Dawson, G.; Chen, W.; Zhang, T.; Chen, Z.; Cheng, X.; Solid State Sci. 2010, 12, 2170.

71. Gong, D.; Grimes, C. A.; Varghese, O. K.; Hu, W.; Singh, R. S.; Chen, Z.; Dickey, E. C.; J. Mater. Res. 2001, 16, 3331.

72. Antony, R. P.; Mathews, T.; Dasgupta, A.; Dash, S.; Tyagi, A. K.; RAJ, B.; J. Solid State Chem. 2011, 184, 624.

73. Fahim, N. F.; Sekino, T.; Morks, M. F.; Kusunose, T. J.; Nanosci. Nanotechnol. 2009, 9, 1803.

74. Montakhab, E.; Rashchi, F.; Sheibani, S.; Appl. Surf. Sci. 2020, 534, 147581 .

75. Filho, P. C. S.; Serra, O. A.; Quim. Nova 2015, 38, 679

76. Cushing, B. L.; Kolesnichenko, V. L.; O'Connor, C. J.; Chem. Rev. 2004, 104, 3893.

77. Yoshimura, M.; Byrappa, K.; J. Mater. Sci. 2007, 43, 2085.

78. Morgado, E. J.; Abreu, M. A. S.; Pravia, O. R. C.; Marinkovic, B. A.; Jardim, P. M.; Rizzo, F. C.; Araújo, A. S.; Solid State Sci. 2006, 8, 888.

79. Byrappa, K.; Yoshimura, M.; Handbook of Hydrothermal Technology; Norwich: Noyes Publications, 2001.

80. Chen, Q.; Zhou, W.; Du, G. H.; Peng, L. M.; Adv. Mater. 2002, 14, 1208.

81. Kasuga, T.; Hiramatsu, M.; Hoson, A.; Sekino, T.; Niihara, K.; Langmuir 1998, 14, 3160.

82. Kasuga, T.; Hiramatsu, M.; Hoson, A.; Sekino, T.; Niihara, K.; Adv. Mater. 1999, 11, 1307.

83. Tavakoli, A.; Sohrabi, M.; Kargari, A.; Chem. Pap. 2007, 61, 151.

84. Nam, C. T.; Falconer, J. L.; Duc, L. M.; Yang, W. D.; Mater. Res. Bull. 2014, 51,49

85. Gonzales, L. L.; Hartwig, M. S.; Fassbender, R. U.; Moreira, E. C.; Pereira, M. B.; Jardim, P. L. G.; Raubach, C. W.; Moreira, M. L.; Cava, S. S.; Heliyon 2021, 7, 1.

86. Preda, S.; Rutar, M.; Umek, P.; Zaharescu, M.; Mater. Res. Bull. 2015, $71,98$.

87. Arifin, K.; Yunus, R. M.; Minggu, L. J.; Kassim, M. B.; Int. J. Hydrog. Energy 2021, 46, 4998-5024.

88. Macak, J. M.; Tsuchiya, H.; Yasuda, K.; Hahn, R.; Baer, S.; Schmuki, P.; Curr. Opin. Solid State Mater. Sci. 2007, 11, 3.

89. Regonini, D.; Bowen, C. R.; Jaroenworaluck, A.; Stevens, R.; Mater. Sci. Eng., $R$ 2013, 74, 377.

90. Feng, Y.; Rijnaarts, H. H. M.;Yntema, D.; Gong, Z.; Dionysious, D. D.; Cao, Z.; Miao, S.; Chen, Y.; Ye, Y.; Wang, Y.; Water Res. 2020, 186, 116327.

91. Bauer, S.; Kleber, S.; Schmuki, P.; Electrochem. Commun. 2006, 8, 1321.
92. Alijani, M.; Sopha, H.; Ng, S.; Macak, J. M.; Electrochim. Acta 2021, $376,138080$.

93. Jaroenworaluck, A.; Regonini, D.; Bowen, C. R.; Stevens, R.; Appl. Surf. Sci. 2010, 256, 2672.

94. Varghese, O. K.; Gong, D.; Paulose, M.; Grimes, C. A.; Dickey, E. C.; J. Mater. Res. 2003, 18, 156-165.

95. Das, P.; Das, S.; Ratha, S.; Chakraborty, B.; Chatterjee, S.; Electrochim. Acta. 2021, 371, 137774.

96. Hu, W.; Li, L.; Li, G.; Meng, J.; Tong, W.; J. Phys. Chem. C 2009, 113, 16996.

97. Song, H.; Jiang, H.; Liu, T.; Liu, X.; Meng, G.; Mater. Res. Bull. 2007, $42,334$.

98. Yuan, Z. Y.; Zhang, X. B.; Su, B. L.; Appl. Phys. A 2004, 78, 1063.

99. Uchida, S.; Chiba, R.; Tomiha, M.; Masaki, N.; Shirai, M.; Stud. Surf. Sci. Catal. 2003, 146, 791.

100. Arruda, L. B.; Santos, C. M.; Orlandi, M. O.; Schreiner, W. H.; LisboaFilho, P. N.; Ceram. Int. 2015, 41, 2884.

101. Jitputti, J.; Suzuki, Y.; Yoshikawa, S.; Catal. Commun. 2008, 9, 1265.

102. Muniyappan, S.; Solaiyammal, T.; Sudhakar, K.; Karthigeyan, A.; Murugakoothan, P.; Mod. Electron. Mater. 2017, 3, 174.

103. Chen, Q.; Chen, L.; Qi, J.; Tong, Y.; Lv, Y.; Xu, C.; Ni, J.; Li, W.; Chin. Chem. Lett. 2019, 30, 1214.

104. Esmat, M.; El-Hosainy, H.; Tahawy, R.; Jevasuwan, W.; Tsunoji, N.; Fukata, N.; Ide, Y.; Appl. Catal., B 2021, 285, 119755.

105. Yu, J.; Yu, H.; Cheng, B.; Trapalis, C.; J. Mol. Catal. A: Chem. 2006, $249,135$.

106. Fang, D.; Huang, K.; Liu, S.; Huang, J.; J. Braz. Chem. Soc. 2008, 19, 1059.

107. Varghese, O. K.; Gong, D.; Paulose, M.; Ong, K. G.; Grimes, C. A.; Sens. Actuators, B 203, 93, 338.

108. Michailowski, A.; Almawlawi, D.; Cheng, G.; Moskovits, M.; Chem. Phys. Lett. 2001, 349, 1.

109. Almeida, L. C.; Zanoni, M. V. B.; J. Braz. Chem. Soc. 2014, 25, 579.

110. Nguyen, Q. A.; Bhargava, Y. V.; Devine, T. M.; Electrochem. Commun. 2008, 10, 471 .

111. Jung, J. H.; Kobayashi, H.; Bommel, K. J. C. V.; Shinkai, S.; Shimizu, T.; Chem. Mater. 2002, 14, 1445.

112. Nowak, M.; Zajac, W.; Hanc, E.; Molenda, J.; Composites, Part B 2021, 213, 108729.

113. Maiyalagan, T.; Viswanathan, B.; Varadaraju, U.; Bull. Mater. Sci. 2006, 29, 705 .

114. Ide, Y.; Nakasato, Y.; Ogawa, M.; J. Am. Chem. Soc. 2010, 132, 3601.

115. Corcoran, D. J. D.; Tunstall, D. P.; Irvine, J. T. S.; Solid State Ionics 2000, 136, 297.

116. Foong, T. R. B.; Shen, Y.; Hu, X.; Sellinger, A.; Adv. Funct. Mater. 2010, 20, 1390.

117. Centi, G.; Perathoner, S.; Microporous Mesoporous Mater. 2008, 107, 3.

118. Fagan, R.; Mccormack, D. E.; Dionysiou, D. D.; Pillai, S. C.; Mater. Sci. Semicond. Process. 2016, 42, 2.

119. Bavykin, D. V.; Friedrich, J. M.; Walsh, F. C.; Adv. Mater. 2006, 18, 2807.

120. Mendes, G.; Bellato, C. R.; Neto, J. O. M. Quim. Nova 2009, 32, 1471.

121. Giahi, M.; Taghavi, H.; Habibi, S.; Russ. J. Phys. Chem. A 2012, 86, 2003.

122. Hoffmann, M. R.; Martin, S. T.; Choi, W.; Bahnemannt, D. W.; Chem. Rev. 1995, 95, 69.

123. Nogueira, R. F. P.; Jardim, W. F.; Quim. Nova 1998, 21, 69.

124. Rao, P. S.; Hayon, E.; J. Phys. Chem. 1975, 79, 397.

125. Kwon, B; Yoon, J.; J. Korean Ind. Eng. Chem. 2009, 20, 593-602.

126. Brito, N. N. d.; Silva, V. B. M.; Revista Eletrônica de Engenharia Civil 2012, $1,36$.

127. Pelizzetti, E.; Minero, C.; Electrochim. Acta 1993, 93, 47.

128. Liu, W.; Wang, M.; Xu, C.; Chen, S.; Chem. Eng. J. 2012, 209, 386. 
129. Pelaez, M.; Nolan, N. T.; Pillai, S. C.; Seery, M. K.; Falaras, P.; Kontos, A. G.; Dunlop, P. S. M. .; Hamilton, J. W. J.; Byrne, J. A.; O’Shea, K.; Appl. Catal., B: Environ. 2012, 125, 331.

130. Silva, G. T. S. T.; Carvalho, T. G.; Lopes, O. F.; Ribeiro, C.; Appl. Catal., B 2017, 216, 70 .

131. Xiong, Z.; Zhao, X. S.; RSC Adv. 2014, $106,61960$.

132. Sehati, S.; Entezari, M. H.; J. Colloid Interface Sci. 2016, 462, 130.

133. Anto, J. A. Nethravathi, C.; Rajamathi, M. ACS Omega 2019, 4, 1575.

134. Wu, Q.; Yang, X.; Liu, J.; Nie, X.; Huang, Y.; Wen, Y.; Khan, J.; Khan, W. U.; Wu, M.; Na, T.; Appl. Mater. Interfaces. 2014, 6, 17730.

135. Mohanty, S.; Moulick, S.; Maji, S. K.; Journal of Water Process Engineering 2020, 37, 101428.

136. Liu, R.; Yang, W. D.; Chueng, H. J.; Ren, B. Q.; J. Spectrosc. 2015, 2015, 9.

137. Backes, C. W.; Scheffer, F. R.; Pereira, M. B.; Teixeira, S. R.; Weibel, D. E. J.; Braz. Chem. Soc. 2014, 25, 2417.

138. Sim, L. C.; Koh, K. S.; Leong, K. H.; Chin, Y. H.; Aziz, A. A.; Saravanan, P. J. Environ. Chem. Eng. 2019, 8, 103611.

139. Guo, L. J.; Wang, Y.; He, T.; Chem. Rec. 2016, 16, 1918.

140. Graves, C. R.; Ph.D. Thesis, Columbia University, United States of America, 2010.

141. Karamian, E.; Sharifnia, S.; J. CO Util. 2016, 16, 194.

142. Kar, P.; Zeng, S.; Zhang, Y.; Vahidzadeh, E.; Manuel, A.; Kisslinger, R.; Alam, K. M.; Thakur, U. K.; Mahdi, N.; Kumar, P.; Shankar, K.; Appl. Catal., B 2019, 243, 522.

143. Parayil, S. K.; Razzaq, A.; Park, S. M.; Kim, H. R.; Grimes, C. A.; IN, S.; Appl. Catal., A 2015, 498, 205.

144. Li, Q.; Zong, L.; Li, C.; Yang, J.; Appl. Surf. Sci. 2014, 319, 16.

145. Bi, Y.; Zong, L.; Li, C.; Li, Q.; Yang, J.; Nanoscale Res. Lett. 2015, 345.

146. Razali, M. H.; Yusoff, M.; Mater. Lett. 2018, 221, 168-171.

147. Liu, M.; Yin, W.; F. J. Qian, F. J.; Zhao, T. L.; Yao, Q. Z.; Fu, S. Q.; Zhou, G. T.; J. Environ. Chem. Eng. 2020, 8, 104061.

148. Wang, X.; Pehkonen, S. O.; Ray, A. K.; Ind. Eng. Chem. Res. 2004, 43, 1665.
149. Quaissa, Y. A.; Chabani, M.; Amrane, A.; Bensmaili, A.; Eletrocoagulation 2012, 36, 147.

150. Fujishima , A.; Honda, K.; Nature 1972, 238, 37.

151. Kudo, A.; Miseki, Y.; Chem. Soc. Rev. 2009, 38, 253.

152. Sun, Y.; Wang, G.; Yan, K.; Int. J. Hydrogen Energy 2011, 36, 15502.

153. Schmuki, P.; Roy, P.; Berger, S.; Angew. Chem., Int. Ed. 2011, 50, 2904.

154. Reddy, C. V.; Reddy, K. R.; Shetti, N. P.; Shim, J.; Aminabhavi, T. M.; Dionysiou, D. D.; Int. J. Hydrogen Energy 2020, 45, 18331.

155. Yu, Z.; Wang, R.; Jia, J.; Yuan, Y.; Wadawik, E. R.; Zheng, Z.; Int. J. Hydrogen Energy 2018, 43, 18115.

156. Feil , A. F.; Migowski, P.; Scheffer, F. R.; Pierozan, M. D.; Corsetti, R. R.; Rodrigues, M.; Pezzi, R. P.; Machado, G.; Amaral, L.; Teixeira, S. R.; Weibel, D. E.; Dupont, J.; J. Braz. Chem. Soc. 2010, 21, 1359.

157. Liu, C.; Wang, L.; Tang, Y.; Luo, S.; Liu, Y.; Zhang , S.; Zeng, Y.; Xu, Y.; Appl. Catal., B 2015, 164, 1.

158. Cao, D.; Wang, Q.; Zhu, S.; Zhang, X.; Li, Y.; Cui, Y.; Xue, Z.; Gao, S. Sep. Purif. Technol. 2021, 265, 118463.

159. Perini, J. A. L.; Tavella, F.; Neto, E. P. F.; Zanoni, M. V. B.; Ribeiro, S. J. L.; Giusi, D.; Centi, G.; Perathoner, S.; Ampelli, C.; Sol. Energy Mater. Sol. Cells 2021, 223.

160. Cho, M.; Chung, H.; Choi, W.; Yoon, J.; Water Res. 2004, 38, 1069.

161. Jiang, Z.; Wang, B.; Li, Y.; Chan, H. S.; Sun, H.; Wang, T.; Li, H.; Yuan, S.; Leung, M. K. H.; Lu, A.; Wong, P. K.; Appl. Catal., B 2019, 257, 117898.

162. Nguyen, N. H.; Tien, K. T.; Hung, T. N.; Xuan, Q. V. N.; Thi, T. H.; Thi, P. L.; Thi, T. N.; Environ. Technol. 2021.

163. Joshi, B.; Regmi, C.; Dhakal, D.; Gyawali, G.; Lee, S. W.; Prog. Nat. Sci.: Mater. Int. 2018, 28, 15.

164. Podporska-Carrol, J.; Panaitescub, E.; Quilty, B.; Wang, L.; Menonb, L.; Pillai, S. C.; Appl. Catal., B 2015, 70, 176.

165. Hajjaji, A.; Elabid, M.; Trabelsi, K.; Assad, A. A.; Bessais, B.; Rtimi, S.; Colloids Surf., B 2018, 170, 92.

166. Patrón-Soberano , A.; Nunez, L. B. P.; Casas, F. S.; Peñas, A. D. L.; Domínguez, R. B. E.; González , G. R.; Photochem. Photobiol. Sci. 2017, 16, 854 . 